Constructing Consumer Knowledge in Market Research:

An Ethnography of Epistemics

\author{
Johan Nilsson
}

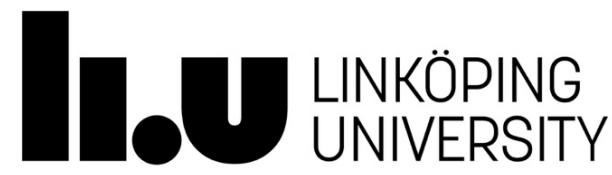

Linköping Studies in Arts and Science No. 735

Faculty of Arts and Sciences

Linköping 2018 
Linköping Studies in Arts and Science • No. 735

At the Faculty of Arts and Sciences at Linköping University, research and doctoral studies are carried out within broad problem areas. Research is organised in interdisciplinary research environments and doctoral studies mainly in graduate schools. Jointly, they publish the series Linköping Studies in Arts and Science. This thesis comes from the Technology and Social Change unit at the Department of Thematic Studies.

Distributed by:

Department of Thematic Studies, Technology and Social Change Linköping University

58183 Linköping

Johan Nilsson

Constructing Consumer Knowledge in Market Research:

An Ethnography of Epistemics

Edition 1:1

ISBN 978-91-7685-360-3

ISSN 0282-9800

(C) Johan Nilsson

Department of Thematic Studies 2018

Printed by: LiU-Tryck, Linköping 2018 


\section{A note on the cover}

The pith helmet on the cover rested on a hat rack in the lobby of the Norna office in Stockholm throughout my fieldwork. For me, it was a source of amusement and curiosity. During my training in anthropology, the pith helmet would be mentioned in jokes and everyday conversations referring to the discipline's colonial heritage of adventure and exploration. I was at Norna as an anthropologist among a group of market researchers who themselves were in a trade associated with both knowledge and manipulation. Who was the pith helmet for? I kept wondering until after my fieldwork was over. The next time I returned to the office, the helmet no longer rested on its rack by the coat hangers. Asking one of my key informants 'Edward' about it, I was told that most likely it had been a prop that 'Alan from Media probably brought for a Christmas party' and that it had simply lingered on after that. I never learned where it went. I do know that my head did not fit it. 



\section{Abstract}

Market research pervades society. It is an endeavour that connects marketing practice with methods similar to social science. Further, market research results appear as knowledge produced to inform recipients towards making productive business decisions and as a commodity sold to commissioning clients. I suggest that such commissioned knowledge production must be approached taking into account both the making and the marketing of such material. The position of market research between concerns to know through research and to market goods and services, including its own, has been approached differently in academic scholarship. Examples range from criticism against surveillance and manipulation, to calls to defining the benefits of market research techniques for organising markets and societies. Researchers have tried to explain this knowledge making for market research as a construction of objects of knowledge or as a performative phenomenon. This thesis takes an ethnographic and cultural approach to market research work and the researchers that undertake it. Based on fieldwork with Swedish firm Norna (pseudonym) and handbooks from industry organisation ESOMAR, the thesis inquires into the epistemic practices and epistemology of market research, how market researchers consider their work influenced by the relations that they maintain and how ideas and practices in market research inform understanding of commissioned knowledge production.

The thesis consists of four articles dealing with the ideas, actors and processes that engage market researchers. The first article assesses market research industry handbooks and discusses the contribution of performativity approaches in light of this local epistemology. The second article studies how market researchers shape their respondents as part of producing consumer knowledge. The third article assesses how the work processes of market research knowledge production rely on the production and distribution of ignorance to successfully keep respondents and clients at the right certainty interval. The fourth article examines client relations and how market researchers produce materials to satisfy clients as well as shape clients' preferences and understanding.

The findings of the thesis point to how market research features its own local epistemics and reflexivity on the part of researchers, but also the tensions and ambiguities involved. Market researchers handle commercial pressures and epistemic quandaries in parallel and overlapping relational practice through the production and deployment of both knowledge and ignorance. Dealing with clients and respondents transcends the distinction between the commercial and the informative. The text informs a further understanding of market research, its techniques by means of engaging with how its researchers view this activity. Further it challenges the social study of knowledge production by showing how in this case it includes concerns that are not simplistically commercial or epistemic.

Keywords: market research, commissioned knowledge production, epistemics, Sweden, marketing, ESOMAR, ethnography, epistemography, epistemic culture. 


\section{Sammanfattning}

Marknadsundersökningar är en verksamhet i gränslandet mellan marknadsföring och samhällsvetenskapliga forskningsmetoder. Det material som marknadsundersökare tar fram ska både informera kunder och säljas till dem. Denna uppdragsbaserade kunskapsproduktion måste förstås både som kunskaps- och marknadsföringspraktik. Det är en dubbelhet som har hanterats på skilda sätt i tidigare forskning. Kritiker har diskuterat marknadsundersökningar som del av en manipulativ marknadsföringsindustri medan försvarare snarare förordat förbättrande av kunskaper kring människors behov. Skapandet av kunskap i marknadsundersökningar har ömsom setts som en konstruktion och ömsom diskuterats som ett fenomen där beskrivningen formar det som beskrivs.

Avhandlingen tar sig an marknadsundersökningar genom en etnografisk studie av marknadsundersökare och deras arbete. Med utgångspunkt i handböcker från branschorganisationen ESOMAR, samt deltagande observation på det svenska marknadsundersökningsföretaget Norna (pseudonym), diskuteras marknadsundersökningar utifrån en rad fokusområden: Utsagor om kunskap såväl som praktiker i kunskapsproduktion, hur marknadsundersökare ser sin verksamhet i relation till kunder och respondenter samt hur undersökningar görs säljbara och användbare för uppdragsgivare.

Avhandlingen innehåller fyra delstudier som i form av artiklar studerar olika aspekter av marknadsundersökningsarbete. Den första artikeln studerar handböcker från ESOMAR och undersöker vilket bidrag som kan göras vid analys givet att undersökarna själva formulerar idéer om sin verksamhet. Den andra artikeln handlar om hur marknadsundersökare formar deltagare i undersökningar som del av sin produktion av kunskap om konsumenter. Den tredje artikeln går igenom Nornas arbetsprocess med fokus kring hur kunskapsproduktion också handlar om att generera okunskap för att respondenter och kunder ska kunna förstå och delta. Den fjärde artikeln avhandlar relationen till undersökningens beställare och hur marknadsundersökare formar sitt material för att tillfredsställa kunden, samtidigt som deras preferenser formas för att producera ett gott mottagande av undersökningsresultat.

Avhandlingen visar hur marknadsundersökningar karaktäriseras av förutsättningar för kunskapsproduktion och hur marknadsundersökare själva är reflekterande kring sitt arbete. Den ambivalens och de spänningar som kännetecknar marknadsundersökningar som verksamhet diskuteras $\mathrm{i}$ termer av hur marknadsundersökare samtidigt hanterar kommersiella såväl som kunskapsteoretiska aspekter av arbetet. Genom att fokusera på hur marknadsundersökningar är en relationell verksamhet visas också hur marknadsundersökare hanterar spänningar mellan vikten av att göra undersökningar som hjälper kunden och att få kunder att köpa undersökningar. Genom att utgå från hur marknadsundersökare själva ser på dessa frågor ger studien en sammanvägd bild av hur uppdragsbaserad kunskapsproduktion handlar om såväl relationsarbete som att skapa kunskap som beskriver marknader och konsumenter.

Nyckelord: marknadsundersökningar, uppdragsbaserad kunskapsproduktion, det epistemiska, marknadsföring, ESOMAR, etnografi, epistemografi, kunskapskultur 


\section{Acknowledgements}

This thesis is the result of effort and support from many people. First of all, I want to thank my informants at Norna. Without them this project would not have happened and I very much enjoyed my time doing fieldwork.

I am immensely grateful to my thesis supervisors. CF Helgesson has been a fantastic mentor from the start, offering sagely advice on all aspects of becoming a researcher. Lotta BjörklundLarsen, my secondary supervisor has kept my energy up, given me a footing in anthropology beyond the texts and offered generous input to writing ethnography. Thank you both for being friends and role-models.

Many people at Tema $\mathrm{T}$ have offered support during my $\mathrm{PhD}$ training. It has been a great environment to work in, full of passionate and funny people. Thank you all. Francis Lee has been a supportive friend and colleague. I would not have the same understanding of research if it were not for his input and advice on the nitty-gritty of academic survival. My fellow $\mathrm{PhD}$ students have been a source of continuous support. In particular, I want to thank Katharina Reindl for sharing an office and many good times as well as Lisa Lindén, Ivanche Dimitreviski, Nimmo Osman Elmi and Darcy Parks for camaraderie and aid. I have also thoroughly enjoyed my time with the $\mathrm{PhD}$ cohorts preceding and superseding mine. The already established doctoral students were generously passing on their knowledge about doing a $\mathrm{PhD}$ and the succeeding $\mathrm{PhD}$ students have been great friends and support. Thank you.

I want to express my gratitude to the ValueS seminar and its regular participants over the years: CF, Ivanche, Francis, Lisa, Lotta, Nimmo, Réka Andersson, Baki Cakici, Jeffrey Christensen, Maria Eidenskog, Vasilis Gallis, Oscar Javier Maldonado, Sonja Jerak-Zuiderent, Linus Johansson-Krafve, David Moats, Fredy Mora-Gámez, Karin Thoresson, Else Vogel, Anna Wallsten, Steve Woolgar and Teun Zuiderent-Jerak. Thank you for showing me the ropes, for expanding my tastes and for all the discussions.

The participants in my 60\% seminar and the final seminar played a vital part in shaping this thesis. Thank you, Francis, Martin Hultman, Corinna Kruse, Jenny Palm and Harald Rohracher. My two namesakes Johan Lindqvist and Johan Hagberg acted as opponents in each respective seminar and they did a fine job. I appreciate all the pointers and suggestions! 
I owe thanks to Ian Dickson for keeping me running, to Josefin Frilund for many pleasant chats, to Louise Kelpe for help with the cover and to Pat Baxter for patient language editing.

Having a dispersed network of junior academics helps when trying to write a dissertation. My old friend Niklas Svensson and I have worked together on our respective $\mathrm{PhD}$ projects in tandem. He knows my texts inside and out and has given great support and criticism. My more recently found friend Jonas Båăth and I have shared both interests and texts. I would not have got into the $\mathrm{PhD}$ without the NUI Maynooth postgrad students, many of whom are now doing their own PhDs: thank you Rebekah McCabe, Anthony Kelley, and Ting-Ting Shum. Best of luck Will Peat! I am also grateful to the Stockholm University Anthropology Beer Cluster for fun and solidarity.

Several other academics have offered assistance and insight. Thank you, Hans Kjellberg for good advice and LancStock, to Robin Williams, Gianmarco Campagnolo and Neil Pollock in Edinburgh, to Marianne Lien and Sergio Sismondo for the helpful notes on early article drafts, to Helena Wulff for sticking her neck out for me for years, to Steve Coleman and Pauline Garvey for helping me with my masters and keeping me fascinated with anthropology and to Daniel Normark for taking an interest in an ethnography that sort-of-kind-of deals with consumption.

All my thanks to my friends and loved ones: to Sarah Walsh and her lovely parents Tony and Heather, to Guldlaget and Melrose.

I am forever indebted to my loving family: My parents Anna-Kari and Anders who let me write up at their home office and to my siblings Gustav and Karolina. More support than from anywhere else comes from my beloved Yonna and our wonderful son August. Thank you for everything. 


\section{Table of Contents}

Abstract $\ldots \ldots \ldots$

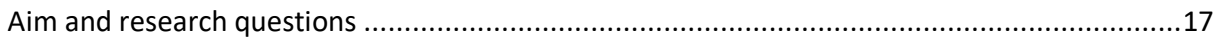

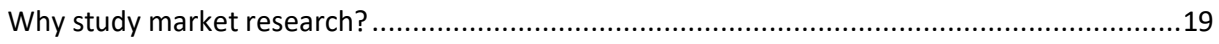

Decisions are located within entities that are known through market research ..............................20

Marketing knowledge lies in between the pragmatic and the realist .........................................21

It is an arena for making order in the world with which many people take issue...............................21

Market research says something important about the influence of knowledge and knowledge making

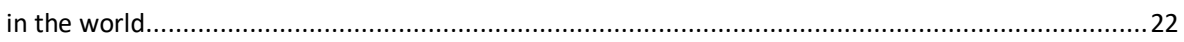

Studying market research paves the way for thinking critically about marketing ............................23

It is premature to think about market research as an entity without taking into account how it works

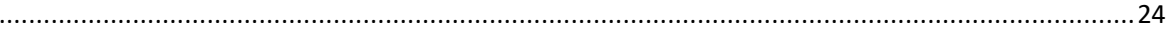

Taking stock - dealing with the uncertainties of market research ................................................2 24

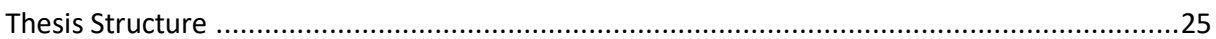

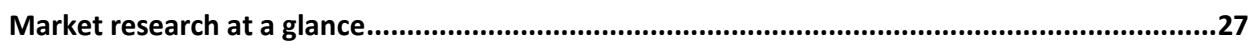

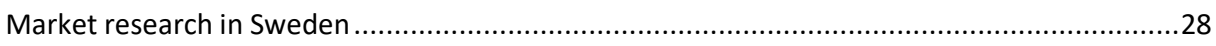

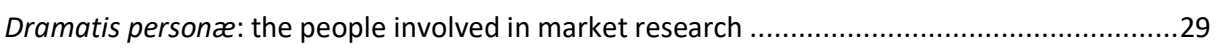

A brief outline of fundamentals of market research work ............................................30

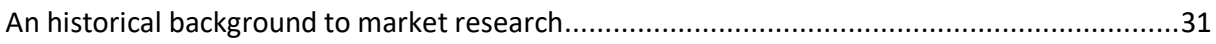

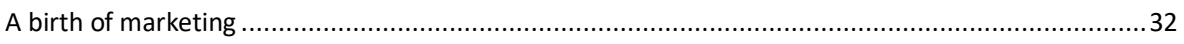

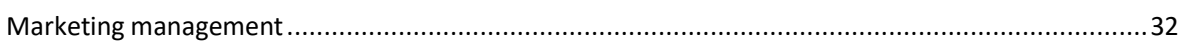

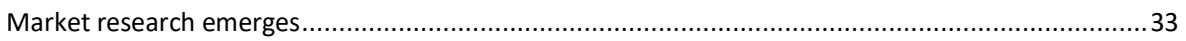

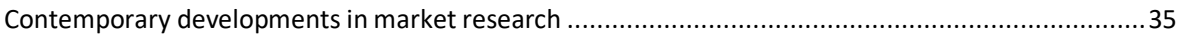

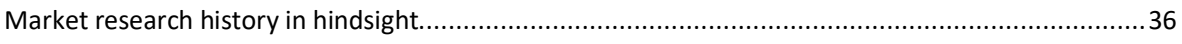

Previous Investigation into Market Research as Knowledge Making......................................37

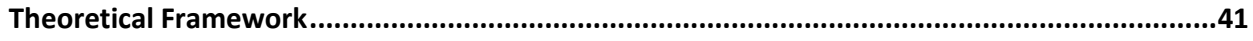

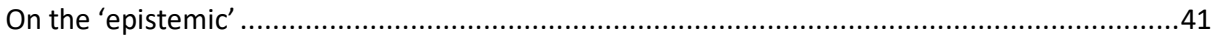

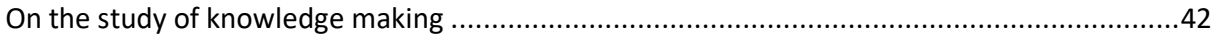

The cultural as a tool for inquiring into the epistemic ................................................42

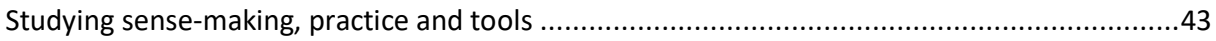

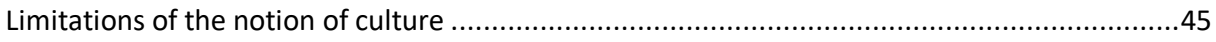

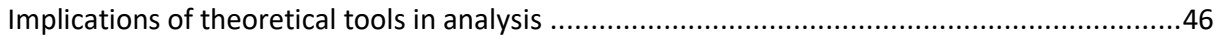


Methods and Engagement: ESOMAR, Norna and Researching Researchers .............................49

Studying market research epistemics in ESOMAR literature ..........................................49

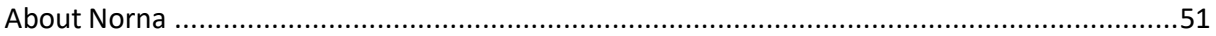

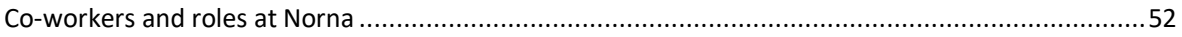

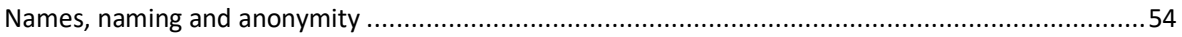

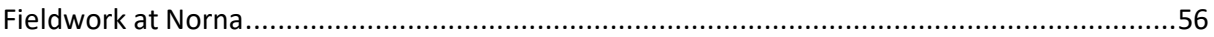

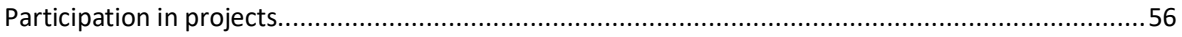

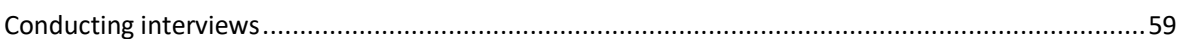

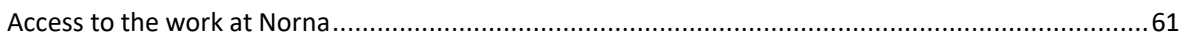

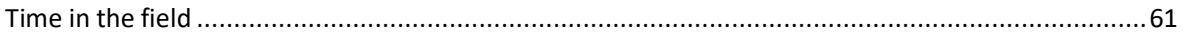

Focusing on 'qual' over 'quant' and senior managers over junior managers ...................................62

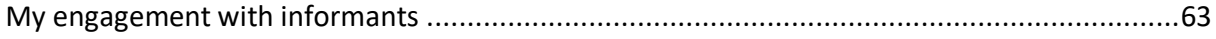

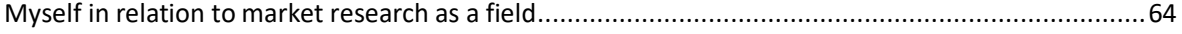

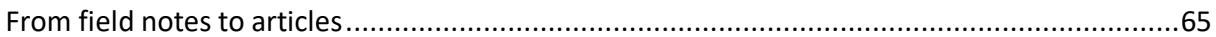

Article Summaries........................................................................................................69

Article 1 'Epistemologies in the Wild: Local Knowledge and the Notion of Performativity' ........69

Article 2 'Producing Consumers: Market Researchers' Selection and Conception of Focus Group

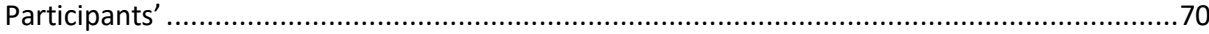

Article 3 'Practices of Not Knowing in Market Research Knowledge Production' .....................72

Article 4 'Know Your Customer: Client Captivation and the Epistemics of Market Research' .....73

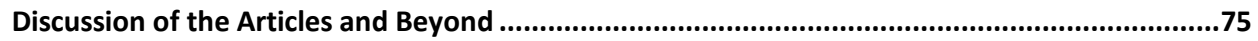

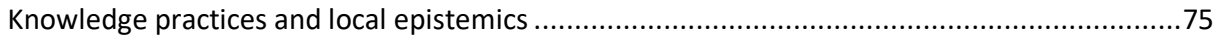

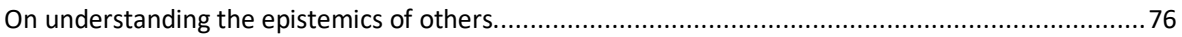

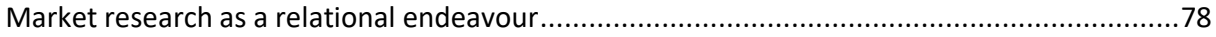

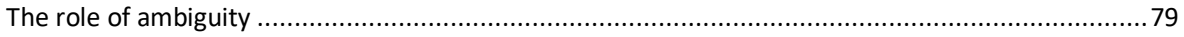

Understanding commissioned knowledge production in market research ...........................82

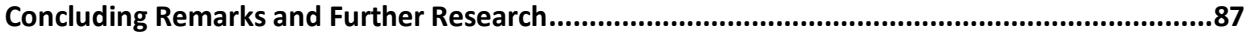

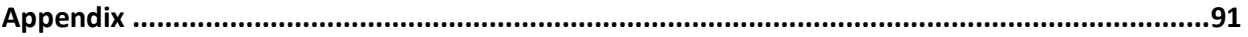

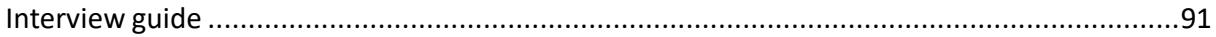

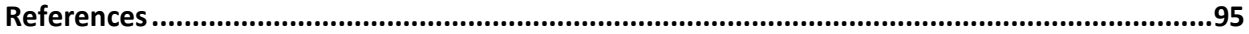




\section{List of constituent papers and co-author statement}

Four articles contribute to this compilation thesis. Article 1 handles explicitly articulated epistemological arguments in industry handbooks. Article 2 covers how market researchers deal with respondents who are to speak on behalf on consumer segments. Article 3 inquires into the market research work process from the perspective of production of knowledge as well as 'ignorance'. Finally, Article 4 discusses how market researchers position the contribution of their work in relation to clients.

1. Nilsson, Johan, and Claes-Fredrik Helgesson. 'Epistemologies in the Wild: Local Knowledge and the Notion of Performativity.' Journal of Marketing Management (2015).

2. Nilsson, Johan. 'Producing Consumers: Market Researchers' Selection and Conception of Focus Group Participants.' Under review with Consumption Markets and Culture. Originally submitted December 2015.

3. Nilsson, Johan. 'Practices of Not Knowing in Market Research Knowledge Production.' Submitted to Journal of Cultural Economy.

4. Nilsson, Johan. 'Know your Customer: Client Captivation and the Epistemics of Market Research.' Under revision for Marketing Theory. Originally submitted March 2016.

As noted in 'Epistemologies in the Wild' I gathered, processed and analysed research materials. The subsequent writing and conceptualisation of the article was an endeavour shared between Claes-Fredrik Helgesson and me. 



\section{Introduction}

Market research pervades society. It spans marketing as well as the social sciences in its ambition to understand the features of markets and consumers. Market research outcomes help shape environments, products and social situations. To imagine a world full of marketing and market research is not to envision the remote beach that anthropologist Bronislaw Malinowski asked his readers to imagine arriving to in the seminal ethnography Argonauts of the Western Pacific (Malinowski 1961). It is instead to think about your local supermarket. Walking around the aisles you are surrounded by an environment and objects that are all deliberately shaped by ideas about you as a shopper or consumer. Picking up something like a bottle of liquid soap, you are gazing upon an object prepared for your perusal and selection. Not only is the bottle a work of automated industry and design, it is very likely that the name on the label and shape of the bottle, as well as the scent of the liquid therein were all carefully considered and tested (e.g. Desroches 2011; Muniesa and Trébuchet-Breitwiller 2010). It could perhaps be said that the soap is not directed at you specifically and you were probably not the one responding to the research efforts. Still, someone responded and contributed to an idea about consumers that involves you. Notions about consumers, held by marketing professionals, informed the product you hold in your hand (Berghoff et al. 2012; Schleifer and DeSoucey 2015). In short, our world is infused by market research and the decisions informed by it.

Further interest in consumers surrounds you in the supermarket. The shop is planned according to ideas about shoppers' behaviours (Cochoy 2011), and your eventual purchases will be analysed as part of customer databases to refine their idea of you and what you and your fellow shoppers want, so that new and more appealing products may be suggested for you in the future (Kotler et al. 2016). Beyond the shop your participation in society as a user of healthcare, public transportation or other services, are informed by similar techniques (Osborne and Rose 1999). Your preferences matter to professionals who want to make the most profitable decisions in dealing with you (Kotler et al. 2016). Information about what we as consumers, citizens and users think and like are even collected by market researchers to make the news by publicising reports about our practices and preferences where companies can feature as sources of knowledge, e.g. an insurance company may release reports about what worries children or small business owners and have findings reported on as news (cf. Baltscheffsky 2012; Hedlund 2011).

We are all in contact with the outcomes of market research and many of us have participated as respondents. Active responses include customer satisfaction surveys, taking part in focus groups 
(Lezaun 2007; Tadajewski 2015) or trying product samples (Muniesa and Trébuchet-Breitwiller 2010). Beyond that, we are monitored by our customer memberships (e.g. Breddam 2015), internet browsing histories (Cheney-Lippold 2011) or movements in public spaces (Cochoy et al. 2015). Market research is pervasive and consequential work.

But what is market research, as a field of inquiry and business? This thesis explores how market researchers reflect about how they make knowledge, the routines they have for doing so, and their assumptions about other actors (e.g. respondents, clients, consumers) that their work involves. Often the term 'consumer' is merely marketing shorthand for 'people', and questions about consumers are in effect queries about humankind (see for instance Canniford and Shankar 2012; Thompson and Hirschman 1995). It is relevant to keep this in mind in order to see the connection between making sense of consumers and making sense of people in general. I have set out to look at market researchers and see them as a case of researching people researching people (cf. Hacking 1999). Market research constitutes a range of ways in which some actors in contemporary societies establish what people are like. However, the workings and interpretations that these activities involve are not widely discussed or even given much consideration. When particular attention has been paid to market research as a method to know consumers and markets, sensationalist claims of uncanny insight and control have dominated the discussion (e.g. Packard 1991). To amend this, I am focusing on market researchers and their knowledge making as cultural - that is, as actively interpreting and reflexive about their practices, tools and environments. The framing of market researchers' knowledge as a cultural matter draws attention to the tools and people involved, as well as the ideas and models that guide questions and answers. Market researchers are involved in a larger world of marketing, and much of their conceptualisation of market research knowledge takes the discipline's connection to decision making to heart (ESOMAR 2007; Kotler et al. 2016).

In order to understand market research as 'cultural' it is also important to grasp its surroundings, including the organisation around commissioning clients and the framing of the respondents who produce the basis for consumer knowledge. Attention must also be placed on the materials that play a part in market research work, and the situations that market researchers set up to gain material. Simply put, appreciating market research comes down to what I mean when I suggest considering market research and its researchers as cultural: researchers are reflexive and involved in particular and interconnected ways of thinking, using particular tools in particular environments and settings. Market researchers are aware of the tensions involved in their work. 
They have concerns over how their work is best performed, what it ought not to be, and to what extent it resembles the sciences which it purportedly applies rather than practices outright (ESOMAR 2007; Hamersveld and de Bont 2008; Mouncey and Wimmer 2007). Instead of resolving these tensions through a priori definition this thesis will treat market researchers' formulations and approaches to doing research as an analytical resource.

An important analytical theme in this project lies in the ambiguity of the product of market research. Such ambiguity involves both what kind of activity market research is, and what ends it strives towards. This ambiguity is not only something that interests me for the purpose of analysis. It features in other academic attempts to describe market research and its effects. It is also something that provides some tensions for my informants, both when they express concerns in everyday activity and when I discuss their work with them. It is the tension between market research as an activity that results in knowledge, or an activity to produce a commodity, respectively. As noted by Berghoff et al.:

Market research data becomes information when it is used for marketing purposes and a commodity when it is sold. But it is not clear when it becomes knowledge or if it ever does so. Knowledge demands depth and context, and marketing literature all too often uses knowledge and information interchangeably.

(Berghoff et al. 2012: 11)

In most situations renderings of market research results both as knowledge and as a product are relevant, but there are situations where one is emphasised over the other. An agnostic sensitivity to this tension opens for a productive foray into market research as it is discussed in several strands of research. In particular, how it manifests and is dealt with by my informants is relevant to discussions in anthropology (Strathern 2006), science and technology studies (STS) (cf. Callon 2005; Latour 2005; Lynch 2000, 2013) and the market studies field in which such approaches are used together with marketing as well as economic sociology to study market organisation and business practice (Araujo et al. 2010; Cochoy 2009; Geiger et al. 2014).

With market researchers involved in knowledge making, it is worthwhile to study such work while taking into account its ties to marketing and business practice. Market researchers are involved with describing markets and consumers, ostensibly for the purpose of strengthening business decisions (ESOMAR 2007; Kotler et al. 2016), e.g. what new products to introduce, new packaging or advertising concepts, and so on. This offers an opportunity to examine market research work in relation to how studies of markets have performative effects on the markets that purportedly are described (Callon 1998; MacKenzie et al. 2007; Mason et al. 2015). It is also 
vital to acknowledge the particularities of marketing (Cochoy 1998; Kjellberg and Helgesson 2006, 2010; Mason et al. 2015) in relation to other forms of economic description (MacKenzie and Millo 2006), market organisation (Callon 1998) and economics (MacKenzie 2007). This study draws upon some of the debates and developments of this area of study and attempts to contribute to it. It will, however, maintain an overarching cultural perspective to guide my own inquiry. Viewing market researchers' epistemic statements and practices through a cultural lens shows their sophisticated reflexive competence. This means attention to the holistic and particular arrangements of people, how they produce results and reports, using techniques such as surveys, interviews and focus groups to inform commissioning clients, but also acknowledging how they make sense of practices, tools and environments. Market researchers theorise about both their objects and recipients of research and give consideration to how the accounts they produce inform business.

At times market researchers imagine their work as a largely realist endeavour, meaning that it is characterised as an activity of finding out about the world. Such an idea of market research has been influential both when the industry is advocated (Bogart 1957; Woodward 1951) and when it is criticised (Packard 1991). As this thesis will show, market researchers themselves often relate to this rendering of what they do, even when they challenge it. There is also significant work in seeing how market research, like other research in the sciences, constructs objects of knowledge even if it purports to study them (Grandclément and Gaglio 2011; Heiskanen 2005; Sunderland and Denny 2011). It is possible to gleam further aspects of market research by studying researchers, and how they relate to objects of knowledge, objects of research and epistemic subjects (Knorr Cetina 1999) in respondents and clients. For instance, as noted in Article 2, the selection of respondents in focus groups has to do with selecting good research participants for the sake of producing good end results. It shows how interesting outcomes matter a lot to researchers, even if they speak about their selection in terms of avoiding false input.

To understand market research as an activity, and make sense of its ends, it is important to pay attention to how market researchers deal with their clients, consider issues of quality of research, purpose of market research activity, etc. The mission of market research to produce knowledge to clients for marketing purposes prompts questioning whether there is a difference between satisfying the client's wants, needs and reception of materials and the effort towards informing them. Similarly, the extent to which the client has to be known and considered for market researchers to help them merits further inquiry. In this, the work and product of market research 
has to be considered in tandem with the relations through which it works. In order to understand what market research produces the particular assumptions and work processes, but also the relationships between involved actors, all matter.

\section{Aim and research questions}

The aim of this thesis is to further understanding of commissioned knowledge production by exploring how market research processes make knowledge. By the term 'commissioned knowledge production' I mean the making of knowledge on behalf of a receiving party. In particular, I take interest in the assumptions of knowledge making in market research. This is in order to approach market research as an important site for the making of markets, which can be further understood by drawing on perspectives from STS, anthropology and the sociology of economics and marketing. It also strives to use the market research case to think about how knowledge making can be studied - particularly in situations where it is performed in a very pragmatic manner.

I will discuss the epistemics of market research with interest in how objects of research and research output are affected. Apart from providing an in-depth ethnographic account of market research, I am interested in unpacking market research as a case of knowledge making about consumers and markets. To do this, I examine discussions about how knowledge and means of producing it affects markets in the fields of market studies and economic sociology (Callon 1998; Zwick and Cayla 2011). As this thesis progresses I will show the importance of ideas about market knowledge and how it is thought to affect respondents and clients. The outcomes of market research cannot readily be separated from the work process, relations and ideas involved in this endeavour.

Further, what I want to achieve is furthering understanding of knowledge making more widely by looking at an area of activity that purports to apply social science. This is a common claim in market research literature (e.g. Belk et al. 2012; ESOMAR 2007; Kotler et al. 2016) and it is sometimes stated by market researchers, too. I find that market research is a case that speaks to discussions within STS and the social study of knowledge making, particularly the shaping involved in descriptions discussed under the notions of construction and performativity of knowledge, respectively (Camic et al. 2012; Latour and Woolgar 1979). This thesis will point to how Mertonian norms about social science (Sismondo 2011) hold some relevance to my informants, but also how their understanding of research is situational and layered. My informants produce material trying to relate results to the methodological hinterlands (Law 2004) of surveys, focus groups, etc. They consider their work to be research and I wish to avoid a 
reading where the output of research is considered 'content-less' or 'arbitrary' (Pollock and Williams 2015). This does not mean that claims of realist ambition of market research work ought to be taken at face value: realism expressed by market researchers and marketing professionals has been described as selective rather than general (Moeran 2004). However, trying to 'expose' the construction of results or setting up market research for comparison with idealised and monolithic 'Science' will fail to account for the nuances of market research work.

Beyond my interest in understanding the making of marketing knowledge, I consider market research as a form of commissioned knowledge production. By that I mean that market research is an activity with pragmatic goals and receiving parties at stake. Often it is a product that is sold on to a paying client, although sometimes the receiving party is located within the same organisation. In market research the material produced is far from disinterested accounts of the state of the world. Material is produced for the purpose of understanding markets in order to better act upon them (Kotler et al. 2016). It is also a good that is sold to clients and in itself an object of marketing.

By understanding market research as a case of commissioned knowledge production, this thesis considers how research outcomes are both products and knowledge. It also acknowledges the role of a commissioning party. In the case of market research this actor is generally a client. Using market research to think with, in order to explore commissioned knowledge production, represents a task for this thesis as a whole, rather than an area of inquiry which can be satisfied by the articles that are included. Instead, thinking with other cases of commissioned knowledge production could potentially include knowledge producers such as analysts (Pollock and Williams 2015), relationships with commissioning recipients such as policy makers or managers, or others who have stakes in the production of material for their use (cf. Camic et al. 2012). Theorising about such objects features considerations that span pedagogy and sales and marketing, as well as concerns over the epistemic aspects of knowledge production.

Informed by accounts of how markets are organised, and how ideas about markets have effects on the markets they purport to describe (Callon 1998; MacKenzie et al. 2007; Zwick and Cayla 2011) I take interest in a related query. I ask how ideas about market actors play into the making of market knowledge. The thesis deals with the knowledge making of market research, through explicit expressions from industry actors (see Article 1), as well as through my ethnographic study 
of a firm I will refer to as 'Norna' in particular (Articles 2-4). The driving research questions, which will be answered through a discussion of the compiled articles, are the following:

I. How do knowledge making practices in market research reflect the local epistemics of such work?

II. How is epistemic work and the epistemological reasoning of market researchers influenced by the relations maintained with research respondents and receiving clients?

III. How do ideas and practices in market research inform understanding of commissioned knowledge production?

Based on perspectives on knowledge making and knowledge makers through cultural lenses I will discuss the making of market knowledge inquiring into the relationships involved, what is assumed about the involved actors, how the product of market research is characterised and handled, how market researchers make sense of their work and how practices, outcomes and objects are shaped by these ideas.

\section{Why study market research?}

Market research is a pervasive feature of contemporary markets, consumption and society. It is also a rich object of study in that it has been considered from different angles by different actors such as market researchers as well as marketing scholars. Market researchers themselves have speculated and theorised about what constitutes good research practice (e.g. Belk et al. 2012; Moisander and Valtonen 2006). Further, scholars of marketing and the social sciences have thought about market research as part of business and marketing practice (Arvidsson 2001; Lien 2004). This study is an example of research treating market research as a topic to understand in order to inform issues of knowledge making, marketing and commissioned knowledge production. In some cases the study of market research has featured auto-ethnographic or similarly local accounts of such practices, blurring the distinction between the role of market researcher and of being an academic researcher (e.g. Heiskanen 2005; Muniesa and TrébuchetBreitwiller 2010; Sunderland and Denny 2011). This study will deal with market research in a way that takes seriously that market research is part of business practice, sold to clients, and at the same time a peculiar form of knowledge making that is subject to reflection on the part of its practitioners.

As I will show in the articles and the discussion, market researchers do not merely present findings but rather strive to shape understanding and relationships with those partaking in their results. This is important because it means particular challenges for researchers to which we have reason to pay attention - if not for the reason of understanding market research properly, then 
because similar challenges face researchers in academic settings: this thesis introduction is not free from efforts to win over those taking part in it. (That means You, dear reader!) Engaging with the knowledge making of others would not be very interesting without the ambition to learn from one's informants. I will therefore borrow presentation techniques not just from academic traditions such as the ethnographic introduction at the beginning of the thesis, but from market research work. In the following section I will present a series of statements in the manner of survey questions to encourage reflection and interest in market research as a topic of study. Feel free to jot down your answers. Of course, as per ESOMAR standards (ESOMAR 2007), answers will not be collected or used without readers' consent! Nevertheless, readers are encouraged to consider their positions throughout this section as they will be relevant when I later take stock of motivations for studying market research.

\section{DECISIONS ARE LOCATED WITHIN ENTITIES THAT ARE KNOWN THROUGH MARKET RESEARCH.}

1. A good way to motivate a decision or explain an occurrence is by arguing that it is what suits consumers, users, customers, people or markets.

[Rate your position on a scale of 1 to 5 where 1 is 'strongly disagree' and five is 'completely agree'.]

The consumer is a character regularly spoken of in its absence, yet it is thought to have a very concrete status as a stable feature of the world. The consumer is often singularised, with assumed, very general traits, but it is in its particularities of preferences and characteristics that it comprises important motivation for business decisions (Paterson 2006). In this, the consumer is an object of knowledge with ascribed existence in a strong sense. Indeed, sometimes marketers and other decision makers locate the basis for their decisions with what they consider knowledge about consumers: justifying choices by what the consumer - or the market aggregated from individuals - wants, needs or seeks. (Cochoy 2005; Schleifer and DeSoucey 2015). A telling example of appealing to the dispositions of consumer markets is the recent controversy over large food companies changing the contents of their drinks in Eastern Europe to include more sugar (Boffey 2017). This gave rise to criticism over lowering the quality of goods sold under well-known brands. Effectively, it was seen as cheating consumers based on their location. However, it was defended by industry spokespersons as a case of legitimate market localisation: 'it is normal practice that manufacturers source ingredients locally and adapt to local tastes' (Boffey 2017). Producing descriptions of such consumer preferences thus has an important impact on how markets are shaped. 


\section{MARKETING KNOWLEDGE LIES IN BETWEEN THE PRAGMATIC AND THE REALIST.}

2. Knowing about markets will translate into profiting from these situations.

[Rate your position on a scale of 1 to 5 where 1 is 'strongly disagree' and five is 'completely agree'.]

Market researchers struggle with the map makers' dilemma of having to make the map less detailed than the real world, yet applicable to devising action (Díaz Ruiz 2014). The empirical study of market research may cast light on how the consumer can be both powerful and useful but at the same time so elusive. Indeed, even if marketing textbooks provide many stable features of consumers (e.g. Solomon 2013), they still have to be researched over and again (Cochoy 2005; Lien 2004). Despite the familiarity of consumers, new questions are posed to (or about) them regularly, and research into consumers is commissioned by a large, and global, marketing industry (Hamersveld and de Bont 2008). A motivation for this thesis lies in curiosity about this industry where new studies continue to reaffirm what consumers are like: it appears that while stable in fundamental make-up consumers are also thought to change outlooks and habits quite rapidly to the point where the distinction between depths and surfaces becomes murky. They are the object of an ongoing production of transitory knowledge (Pollock and Williams 2015) made for the purpose of consumption (Knorr Cetina 2010).

When gaining some insight into the practicalities of consumer research during my work as a consultant prior to my $\mathrm{PhD}$ studies, I began to wonder how conversations, observations or responses from people transformed into 'actionable' consumer insights. Such statements were phrased in a manner allowing for business decisions to be made. Given that market research knowledge appears to be so instrumental, perhaps the key to consumer reassessment lies in the characterisation of market research as producing results that please clients and provide them with certainty or arguments for making a decision.

\section{IT IS AN ARENA FOR MAKING ORDER IN THE WORLD WITH WHICH MANY PEOPLE TAKE ISSUE.}

3. Conceptualising people as consumers is reductive and alienating.

[Rate your position on a scale of 1 to 5 where 1 is 'strongly disagree' and five is 'completely agree'.]

In addition to being interesting for understanding the consumer figure in marketing, market research is a useful case for exploring the issue of knowledge making as a way of establishing order. Of course, the current order of how the world is - including its societies and markets - is 
controversial. The ties between marketing and contemporary capitalist market societies have been subject of rich critical scholarship (e.g. Applbaum 1998; Arvidsson 2005; Tadajewski 2010; Zwick et al. 2008). Market research presents actors with information that is instrumental in marketing action (Arvidsson 2001). It is also worth noting that market research has been used to control markets under other circumstances, such as in the Soviet era Eastern Bloc (Berghoff et al. 2012).

One way of seeing the role of market research is as a form of knowledge that succeeds as far as it conveys a sense of order and comprehension to its recipients. The activity of researching consumers and markets in market research could then be a way of remaking a situation of control for the business actor who takes part of the benefits from this market(ing) knowledge. For those interested in criticising how business is done (as well as for those who seek to do it in novel ways), the making of motivation and control through secure worlds of knowledge ought to be scrutinised. While concerns over market research as a tool of control have been subject to sensationalist or conspiratorial accounts (cf. Packard 1991) it is important not to assume that market research is omniscient.

\section{MARKET RESEARCH SAYS SOMETHING IMPORTANT ABOUT THE INFLUENCE OF KNOWLEDGE AND KNOWLEDGE MAKING IN THE WORLD.}

4. Markets, societies or people are affected by descriptions of social reality.

[Rate your position on a scale of 1 to 5 where 1 is 'strongly disagree' and five is 'completely agree'.]

What comprises a good question or useful answer is a knowledge concern that can be addressed through the study of market researchers. Rather than exploring theory by having it tested against an empirical case, this thesis attempts to understand the role of theorising and sense-making as it is happening in everyday life, using the ideas of market researchers to think with. When the performativity programme of economic sociology seeks to show us that economics plays a vital part in organising markets (see for instance MacKenzie et al. 2007) and marketing (Mason et al. 2015), theories about social reality are not only describing, they may also perform effects. It is reasonable to think about such relationships between theory and practice through the connections that are made by the theory. This calls for seeing theory beyond something that I as a researcher use to guide my interest in a world of people with ideas about the world that are subject to mine (Gupta and Ferguson 1997). Rather, I hope to show that taking people's ideas seriously can contribute to a scholarly work as much as theoretical ingenuity and interest (Traweek 1988). 
The broader motive for the study lies in my interest in commissioned knowledge, and its connection to control. While engaged with research activity (in my view market researchers are not best understood as fabricating results but rather as striving to research something), market researchers are making knowledge. The categories, meanings, values and facts that are produced as part of market research activity are factors in establishing what 'the market' wants: a realm towards which many business people and marketers, as well as politicians and bureaucrats, look for riches, success and control. Even in cases where market research appears to falter in stated aims to describe the world as it is, to inform clients, market researchers keep up with an explicit ambition to make something: people and organisations able to act. I mean this in the sense that what market researchers are really involved with is making clients positioned to be able to make decisions, by showing them the market in a way that the client may grasp their situation as a threat, opportunity or meaningful choice (cf. Ariztia 2015).

\section{STUDYING MARKET RESEARCH PAVES THE WAY FOR THINKING CRITICALLY ABOUT MARKETING.}

5. 'Markets' are concrete entities that may be predictably studied and manipulated.

[Rate your position on a scale of 1 to 5 where 1 is 'strongly disagree' and five is 'completely agree'.]

Knowledge about the market does not just happen. There is something distinctly off about a view of market information where marketers and other market actors (e.g. businesses, regulators or advocates) simply receive feedback from the market. This is especially the case if one posits that the market somehow answers in the form of action-enabling information. Market research is at present an industry that creates information on market states and consumers for strategic business use (Berghoff et al. 2012). Surely 'the market' does not simply respond, but at most presents the careful observer with a chance to produce an account of what it is like? To study market research actualises queries concerning marketing or business and their interactions with the wider world. With the rise to prominence of the marketing discipline in business, the consumer has increased in importance, as target for action and possible beneficiary of relationships with companies. Successful marketing and doing business relies on knowledge of 'the market', as well as its constituent units. So, while doubting that describing markets is as straightforward as collecting facts preceding study and then arriving at what things are really like, I also believe that market research may produce materials that prepare clients for marketing decisions. Market action is not readily separable from efforts to describe markets for the purpose of action (MacKenzie and Millo 2006). 


\section{IT IS PREMATURE TO THINK ABOUT MARKET RESEARCH AS AN ENTITY WITHOUT TAKING INTO ACCOUNT HOW IT WORKS.}

6. Market research is a good thing.

[Rate your position on a scale of 1 to 5 where 1 is 'strongly disagree' and five is 'completely agree'.]

A reason for the serious study of market research is that it is often simplified when described, both by champions and detractors. As market research has been the object of academic study it has often been considered as a relatively collected entity. The features of this reified object may be assumed and most importantly, many academic studies of market research have used a realist framework of understanding this research (Nilsson 2013). Critics of marketing and market research (e.g. Andrejevic 2005; Bauman 2013) may challenge the benevolence of market research techniques, but they appear to agree with the industry affiliated champions of market research (e.g. Bogart 1957, 1963) in the assumption that consumers are out there as pre-existing objects of study or overlook how insiders to this knowledge production may be quite reflexive about their work.

\section{Taking stock - dealing with the uncertainties of market research}

This section has posed questions as well as argued for the relevance of studying market research. Before proceeding, readers are encouraged to take stock of the statements posed above about market research under each of the listed motivations. Do you agree? To what degree, and what does that mean? The answers to questions like these are used to interact with you, produce reports and plan production of commodities and services to sell to you. To those who find it difficult to position themselves according to these directed statements, I would encourage them to engage further with this predicament. How do you voice your concern within the confines of this effort to quantify your position? Consider how knowledge about people may happen through confronting respondents with questions and how the way they are set up factor into the results. Simply put: the workings of market research matter.

Regardless of one's opinion on market research, it is a phenomenon to be understood in its own right. As argued in this section, market research has an important role in statements that matter in marketing decisions. The descriptions that are produced by market researchers are at once meant to capture reality and inform action. These comprise two related but not completely symmetrical goals. The connections between market research, marketing and contemporary capitalism are not a trivial matter. However, neither are the general problems of the link between 
description and action, or between objects of knowledge and objects of study. Given this consequential nature of market research, and the larger issues it involves, it is ripe for receiving comprehensive ethnographic inquiry into its inner workings.

\section{Thesis Structure}

The overall structure of this introductory chapter sets out to first give a brief account of some general characteristics of market research. I will then discuss the research context of this field, specifying to what I see this thesis contributing. Then will follow an outline of the main theoretical tool that I bring to this research context and empirical field - the cultural approach of anthropology and ethnographic studies of knowledge making. The introductory chapter continues with a description of my objects of study: ESOMAR handbooks and Norna, as well as my methodological approach to both. Following the methodology section I will briefly summarise the constituent articles and then discuss their contribution to the study of market research and knowledge making more generally. Finally, I will conclude with a brief outline of the overall implications of this work. 



\section{Market research at a glance}

For readers who are not familiar with market research this section will give a brief outline of this type of activity. Focus will be on how market research is defined by industry actors, but also what professional roles it features; an account of how market research work processes are generally characterised; and how market research approaches have developed over time. Market research has come to form a collection of ways to make knowledge about markets in which these entities exist. An example of such a definition that clearly notes the application of scientific principles comes from the European Society for Opinion and Market Research (known now simply as ESOMAR):

Market research, which includes social and opinion research, is the systematic gathering and interpretation of information about individuals or organisations using the statistical and analytical methods and techniques of the applied sciences to gain insight or support decision making. (ESOMAR 2007: 5)

Market research is given an inclusive characterisation by ESOMAR in this example. It encompasses at least what can be referred to as opinion research (studies of public opinion) and consumer research. This thesis generally uses 'market research' as a concept that includes consumer research (researching consumers). Market research also overlaps with business intelligence such as assessment of business numbers, and figures with less emphasis on collecting materials and more focus on data as something given (cf. Bell et al. 2015). Accordingly, market research deals with researching states of the market, including reception and features of its constituents, possibly down to the level of individuals, such as customers, consumers or households.

Research into consumers, markets, marketing, etc. happens both in academic settings and in more commercial contexts. Market research can then be argued to be a particular kind of marketing research activity. This separation of spheres is not complete but overlapping. A researcher may be occupied both with publishing in academic journals (e.g. Journal of Consumer Research; Journal of Marketing Research) and with doing commissioned work for businesses and organisations (Belk et al. 2012). As researchers may move between the two types of production (with different approaches to research ethics, confidentiality, peer review, writing styles, presenting and publication), the argument whether a researcher is an academic researcher or a commercial market researcher has more to do with practice and publication history than any rigid distinction between professions (cf. Moisander and Valtonen 2006; Moisander et al. 2009). My market researcher informants talk about their work in terms suggesting inquiry ('undersökningar') 
which is deemed related but separate from research ('forskning'; 'vetenskap') in the more academic or science-oriented sense. That said, they typically hold university degrees and at least one of my informants has lectured and written about market research techniques.

Given how inclusive ESOMAR's definition is, it is worth noting that for the purpose of studying market research at a specialised market research firm such as Norna, it tends to be virtually whatever research market researchers happen to do as part of a commissioned project. What is relevant to this thesis is primarily the inclusion of principles of knowledge making in the definition: the idea that market researchers apply science, and that the product of research is meant to help recipients to reach their goals (Hamersveld and de Bont 2008; Mouncey and Wimmer 2007). ESOMAR's mention of decision making as an end of market research frames the production of market knowledge in direct relation to executives and decision makers, who rely on such knowledge in order to act. Though this sounds like market research is close to processes of making products or decisions about how to market them, research is generally commissioned by marketing managers and may often remain a marketing communication issue rather than something affecting the course of a company at large.

The market research projects I encountered at Norna regularly strove for other things than informing future decisions. For instance, market research may be commissioned to audit previous marketing efforts, to defend a decision already made, to spark discussion, or to be used as a basis for communicating the results in the form of content driven marketing. Use of market research as a basis for the building of a brand by producing information about markets or their constituents and then present it to journalists as news (e.g. Hedlund 2011) is also a vital alternative to paid advertising. Market research can be performed 'in house' by a specialised department within an organisation or it may be commissioned from professional firms. The firm where I undertook my fieldwork is an example of the latter. My informants at Norna not only make marketing knowledge but they pervasively market their own services in competition with other firms.

\section{Market research in Sweden}

While it is a small country, Sweden is an interesting region for those interested in market research as it has a relatively large market research sector. In 2005 Sweden had the second highest per capita expenditure on market research in the world, only surpassed by the UK (Hamersveld and de Bont 2008: 54). Hence, I have studied market researchers in a country that is very preoccupied with market research. In terms of a tradition of surveillance of its public, Sweden has undertaken 
population records since the seventeenth century (Ruppert 2012) contributing to a long line of organised descriptions of populace and their characteristics. According to Swedish market research industry organisation SMIF, the market research business employs approximately 2,500 people as of 2016 (Mattias Strandberg, chairman of SMIF, personal communication, 20 Nov 2017) but estimates including temp workers may skew as high as around 5,000 (Anna Broback, former chairman of SMIF, personal communication, 20 Aug 2015). The industry consists of around 100 specialised firms, although it is dominated by a handful of large actors, several of which are part of international companies and groups (Anna Broback, personal communication, 20 Aug 2015). Counting all companies registered in the Swedish Companies Registration Office that claim to work in market research in at least some capacity yields 450 firms, though many of these are not specialised market research companies (Mattias Strandberg, personal communication, 20 Nov 2017). SMIF estimated yearly market research turnover in Sweden to be approximately SEK 3.3 billion in 2015 (Anna Broback, personal communication, 20 Aug 2015) and stated a total turnover for market research in Sweden to be around SEK 3.4 billion to ESOMAR in 2016 (Mattias Strandberg, personal communication, 20 Nov 2017).

\section{Dramatis personæ: the people involved in market research}

If one were to establish who is involved in market research, the simplistic set-up would characterise it as an activity that includes market researchers, their clients (be they internal or external stakeholders) and the people researched. This neglects the issue of the connection between the people researched and the 'consumers' or 'customers', etc. that 'clients' or their representatives are interested in knowing. It is an issue that cannot be solved by providing a priori definitions of these terms. Market researchers have a wide variety of ideas about the relationship between the respondents whom they encounter and with whom they interact, and the people about whom they are meant to create knowledge. The connection can be described as one where respondents are to be representative members of the researched group. Alternatively, it can be discussed as correspondence in the sense of being similar enough to be able to present ideas and attitudes useful for discussing the relevant targeted group. They may also be situational, with terms such as 'customer' meaning different things at different times.

For the purpose of clarity, I use the term 'client' to refer to the actor who receives and commissions market research. This actor can be an individual or organisation. As will be discussed at length in Article 4, what my informants put into the word varies according to the situation. Further, I use the term 'respondent' and 'participant' to describe those people who feature in research projects, without making too many assumptions about their connection to 
categories such as 'consumer'. Indeed, the 'consumer' features in this thesis as an object of knowledge rather than as someone that exits without efforts to describe them. The term 'customer' is used in accordance with how my informants use its Swedish equivalent ('kund) to talk about both those that commission research, and the people that are of interest in the research. This open-endedness of the notion of what comprises a 'customer' is a general challenge to the term and is subject to some exploration in the thesis (see Article 4).

\section{A brief outline of fundamentals of market research work}

Market research projects are a form of research activity undertaken on behalf of a receiving party. Often this recipient is a client external to the group undertaking the research, and the research tends to be bought and sold (Belk et al. 2012; Kotler et al. 2016). Exceptions include organisations with their own internal market research functions. Yet, even in those cases research is undertaken for subsequent use, often by someone other than the researcher. Successful sales meetings lead to definition of a problem that the research firm may solve through a study, which they describe and offer to the client. Projects may use standard or custom research design (Belk et al. 2012). The offering is usually a package at a fixed price, rather than work on retainer. Further, projects may be set up for one client or can be syndicated, with one survey being used to inform several clients. Repeat projects are sought after as they offer the opportunity for projects with less preparation and planning and greater reliability of income. A project offering tends to outline methods, costs, research questions and goals, as well as statements about the methods to be used.

Two concepts are used to demarcate spheres of research methods: for qualitative (sometimes called 'qual' both at Norna and elsewhere) and qualitative research ('quant'). Qualitative methods generally mean focus groups, one-on-one interviews ('deep interviews') or observation. Quantitative methods tend to mean the utilisation of surveys and polls or assessment of business figures (Belk et al. 2012). Both methodological areas rely on interpretation, but qualitative research places greater emphasis on the interpretative process, and quantitative studies often try to minimise the role the researcher's subjectivity plays in the study (Belk et al. 2012). The phase during which research materials are produced is often referred to as fieldwork (Belk et al. 2012). The results that arise are processed (e.g. this processing of results is often thought to refine data into knowledge and is often referred to as 'analysis') and turned into a report, often in the form of a visual presentation (Belk et al. 2012; Moisander and Valtonen 2006). Reports are generally handed over to the receiving client after a workshop or presentation. The report and its reception are very important parts of the research process as market research must strive towards making 
sure that the client has been successfully informed (see Articles 3, 4). Usefulness of results is also an important performance to secure customer satisfaction and repeat business (see Articles 3, 4).

It is worth noting that market research tends to be characterised as a series of discrete stages (e.g. discussion and sales meetings, project set-up, preparing study, fieldwork, analysis and reporting). First, projects are pitched and/or explored in discussions and sales meetings with clients. After that an offering is often made, which upon approval may lead to new meetings and agreement on set-up. After preparing the study, drawing up interview guides, surveys, etc. the researchers undertake fieldwork. Materials produced in fieldwork then undergo analysis which is put in a report and given to the client. This presents a linear comprehensive and foreseeable phenomenon. Indeed, figures similar to it are used as part of sales pitches. In practice however, everyday market research features many considerations and operations that break this strict order (see Article 3): Presenting knowledge at the end of the research process is an achievement that requires researchers to anticipate, as well as shape, clients' preferences (Article 4). Pressure to deliver materials may also lead researchers to circle back to earlier stages should recruitment or research stages prove challenging (cf. Article 2). Ultimately however, the promise to provide results requires researchers to do work that tends to cover the general research process, albeit with regular detours, stops and retraced steps.

\section{An historical background to market research}

While my informants seldom account for the history of market research, they are referring to it. Just as other actors, they take for it for granted in situations such as when the experts in qualitative methods allude to concepts from psychodynamic psychology as common sense or when an account manager casually quotes advertising guru David Ogilvy during a meeting (Ogilvy and Parker 2011). Nevertheless, I have been surprised by the sparse recounting of histories of market research in marketing presentations, everyday conversation or handbooks (Hamersveld and de Bont 2008; Mouncey and Wimmer 2007). Perhaps this can be taken as an indication of a relatively diffuse professional identity. There are historical accounts however, such as the background ascribed to market research in Belk et al. (2012) or Berghoff et al. (2012). The following section will provide a brief background to how marketing and market research have developed over time. 


\section{A birth of marketing}

Beginning a story of market research must take into consideration the larger field of marketing. For one thing, it is difficult to give it a firm starting point. Academic scholarship on marketing features tales of how this knowledge practice began. Hartmut Berghoff, Philip Scranton and Uwe Spiekermann (Berghoff et al. 2012) suggest that depending on definition and interests it is possible to begin the story of marketing as early as in struggles to explain and successfully undertake trading in the Middle Ages, or Early Modern periods. For the purpose of understanding it from a contemporary perspective, however, its institutionalisation and emic formulation may be tracked more specifically to the end of the nineteenth century (Berghoff et al. 2012). Franck Cochoy connects the interest in customers to industrialised production of goods, and rising product output needing outlets (Cochoy 2005). Such marketing had during the late 1800s and early 1900s been relying on ad hoc experimentation and the experience of individual practitioners, and has grown more rigorous with time (Berghoff et al. 2012). Methodological development of marketing happened over time and market research evolved with it.

\section{Marketing management}

Although marketplaces, with merchants and clienteles are old phenomena, the theorisation of a market sphere with fickle customers to be won over is more recent. Cochoy argues that the notion of knowing one's customer in the current impersonal sense (see also Lien 2004) became a way to mitigate the unpredictability of finding outlets for large-scale production:

To make up for the increasing incompatibility between industrial rigidity and market uncertainty, big businesses devised and implemented strategies and arrangements for adapting demand to supply and supply to demand, with the aim of increasing market relation predictability and stability. Inventing a new figure of the customer was the prerequisite for developing this set of strategies and arrangements. (Cochoy 2005: 37)

In order to make sense of the market, businesses would distinguish distinct groups of customers and ascribe them traits which made them particular, rather than part of an abstracted and homogeneous market (Cochoy 2005).

Market research tends to be framed as a commercial venture, and may be criticised as a symptomatic part of consumer society, or capitalism (Miller and Rose 1997). However, it is also a form of elicitation, which has developed as part of governmental planning of resource distribution in settings like interwar and post-war Britain, and the aforementioned use of such approaches in the Eastern Bloc (Berghoff et al. 2012). Matching production and consumption, or buyers and sellers, simply requires decisions about the features of customers and marketing to 
them. Consumers became targets not only of efforts to know them, but to educate and get them to choose (Cochoy 2005). Efforts to educate consumers also included activities to inform people about the features of goods, with laws to combat fraud in foodstuffs established in the early 1900s, and drives to empower consumers in relation to producers: 'consumerism' (Cochoy 2005). Knowledge about consumers and informing people about consumer issues rose as ways of organising markets as much as helping individual businesses to succeed.

\section{Market research emerges}

Market research has been developed in tandem with academic approaches. It draws on both the marketing discipline, and the study of publics and individuals in social science. Marketing was a taught subject in American universities as early as 1902. Such academic marketing was dominated by perspectives borrowed from geography, demography, sociology and psychology - focusing on linking products and consumers, buyers and sellers (Berghoff et al. 2012). Scientific approaches to marketing management further developed over the course of the 1920s (Berghoff et al. 2012; Cochoy 2005). Distinct tools such as focus groups have roots in the group interviewing techniques of Herta Herzog, Robert Merton and Paul Lazarsfeld, developed in the 1920s out of sociological and psychological approaches to group dynamics. After the 1940s Merton coined the term 'focused' interview to describe these techniques of eliciting answers to 'how'-questions from groups of people (Lezaun 2007; Tadajewski 2015). The techniques which Merton, Lazarsfeld, and (less famously) Herzog developed added additional perspectives to studies of audiences and consumers which complemented quantitative approaches to viewing, listening and other habits (Tadajewski 2015).

The 1930s had seen innovation in the use of statistical surveys to represent consumers and markets (Cochoy 2005). These approaches - while developed by academics such as the aforementioned Merton, Lazarsfeld and Herzog - were picked up primarily for applied research measuring advertising and communication audiences rather than academic research and became staples of the market research industry in the 1950s and 1960s (Tadajewski 2015; Belk et al. 2012). During the post-war 1950s marketing began to come into its own as a way of organising business practice (Cochoy 2005). It is also during the decades following the Second World War that marketing became an activity that is to be run on 'scientific principles' rather than the knowhow of luminaries (Berghoff et al. 2012). 
Market research still features assumptions about the traits of consumers from early modelling, based on theories in vogue at the time. For instance, Stefan Schwarzkopf as well as Mark Tadajewski note that during the US advertising and opinion research market of the post-war era researchers such as Lazarsfeld and Dichter were positioning their work in relation to psychoanalytical psychology (Schwarzkopf 2007; Tadajewski 2015), although they refrained from claiming to be consistent with clinical practice. The work of Lazarsfeld to produce models for engaging with consumer subjectivity featured the use of archetypes (e.g. 'the standard consumer'); what he did was to 'distil the core attributes of the consumer into a manageable and managerially meaningful idea' (Tadajewski 2015: 15). Such 'manageable ideas' remain in research practice, for example in the use of consumer personas.

It was also during the 1950s and 1960s that advertising gained conspiratorial, and mythic importance. With Vance Packard's writing on 'hidden persuaders', the notion of the power of advertisers and marketing professionals to manipulate people, on an unconscious level, firmly established the idea of suggestion in advertising in marketing (Packard 1991; Söderlund 2014). It also further popularised notions of a subconscious, which could be tapped into for purposes of manipulation (Miller and Rose 1997). Crucially, post-war consumer society saw proponents and critics alike agreeing on a model of consumer psychology characterised by irrational drives and unconscious desires. By knowing the consumer in detail, the agency of this figure could be won over - whether framed in terms of the identification of 'true' needs or the production of 'false' ones (Miller and Rose 1997).

Efforts on the one hand to understand consumers and on the other hand to influence and shape them are deeply intertwined in marketing and market research. Miller and Rose (1997) have noted how consumer oriented society developing in the post-war era in 1950s to 1970s Britain came to feature significant use of psychoanalytic - but also social-psychological and rational - modelling of the consumer. The psychoanalytical perspective would focus on pleasure and desires, drawing on psychodynamic models, the social-psychological stressing the exploration of shared meaning, symbols, etc. and the rational consumer model would stress the exploration of how consumers evaluate products and services according to preferences and lifestyle. These models came to be combined, mixed and layered in practice (Miller and Rose 1997). 


\section{Contemporary developments in market research}

Recent development in market research involves increased specialisation, digital approaches and struggles to valorise qualitative approaches. Speaking from American cases Javier Lezaun notes the prolific use of focus group techniques during the 1990s and 2000s, observing also that they have become more and more professionalised, with a couple of large businesses running specialised facilities for focus group research (Lezaun 2007). This professionalisation is not necessarily uniform, however. Lezaun notes a difference in how market researchers in the US and in the UK see the role of the location, with a US focus on controlled environments, and UK tradition of doing focus groups in homes (Lezaun 2007). Qualitative studies have come to receive more formalisation in the form of textbooks on qualitative marketing research, that seek to valorise such methods, in relation to the more influential quantitative methods that have dominated the research literature as well as the lion's share of market research business expenditure (Moisander and Valtonen 2006).

Increased use of digital technologies and social media have allowed for market research to expand traditional offerings online, using online surveys, digital ethnography, etc. (Belk et al. 2012; Kotler et al. 2016; Moisander and Valtonen 2006) Further, market research is currently described as under pressure by the rise of digital approaches. Often these are framed as robust and powerful as well as cost-effective means of knowledge making through the generation of data from customer databases and online behaviour, collected and analysed through increasingly effective and cheap computing (Söderlund 2014). The increase in practices that produce digital traces, and the means to amass and analyse this material has made quantitative understanding of customers and consumers a central cornerstone in marketing thought (Kotler et al. 2016). Increased use of devises that produce data on human behaviour when browsing the web, but also from wearing tracking devices and smartphones when moving through environments, mean that new types of information about people is available (see for example Widmer 2016). This happens in tandem with new ways of handling materials using data mining (e.g. Belk et al. 2012), and cheaper and faster data processing and machine learning algorithms (Cheney-Lippold 2011). Such 'data-driven' approaches are seen as the future by evangelists ushering in a new era of heuristic and post-theoretical understanding of the world through the use of big data, algorithms, etc. (Anderson 2008). The other side to this, of course, is the insistence that market researchers can offer expertise in interpreting what all this data means, paving the way for an advisory role (see Articles 1 and 4). As will be noted particularly in Articles 1, 3 and 4, the perceived threat of a 
decreasing profitability of producing information is part of the motivation for turning market research work towards advising and consultation for clients rather than merely providing data.

\section{Market research history in hindsight}

To summarise, this account of the development of market research is a form that has developed over the course of a century. With so much parallel and recursive change, this history may be best understood as more recent approaches layered on top of older methods, thus gradually increasing the number of approaches used. It is not a monolithic scientific programme but a range of activities, some of which are performed for industry use, others for academic publication. Sometimes the same actors move between the role of publishing academic research, and producing research for industry clients (Belk et al. 2012; Moisander and Valtonen 2006). Berghoff et al. characterise market research activity as ultimately ambiguous, stating that:

It seems difficult to judge if these efforts comprise a method or a science. Indeed, these attempts to understand markets seem to be at odds with all pretentions to an exact science or rigorous system. It might be productive to explore this tension. (Berghoff et al. 2012: 11)

Older ideas have often subsided from the assumptions on which researchers may fall back when speculating about objects of knowledge. In order to understand the nature of the market research which I argue that Norna researchers exemplify, I consider it more of a toolbox than a programme. As other actors within this field, my informants may work according to shared forms and organisational affiliations. They do however, espouse an eclectic approach: rather than informed by disciplinary orthodoxy (or strong sense of history) market research activity is characterised by researchers making do, drawing on varying disciplinary backgrounds and common assumptions. 


\section{Previous Investigation into Market Research as Knowledge Making}

Understanding market research from a social scientific perspective has often begun within the marketing field or among those with an interest in marketing. This section will briefly outline how other scholars have interpreted market research. It shows the space for scholarly effort and debate towards which this thesis turns. Marketing and market research may be interpreted as benevolent or nefarious activity. Market research has been given explanations that are instrumental and critical in nature, and the generative aspects of market research have been framed as construction, performance and performativity.

Champions of furthering marketing have discussed the role of market research as a factor in improving market society (Woodward 1951). Critics have likened it to surveillance (Andrejevic 2005), or seen it as an emblematic part of modern capitalism (Applbaum 1998; Arvidsson 2005). At times, market research has been included in a critical discussion of marketing and consumption, such as when showing how consumption as a subject has been shaped by the sciences (Miller and Rose 1997), or when consumer segments (that is, images of what the market and its constituents are like) are mobilised in the shaping of markets (Arvidsson 2001). Such perspectives on market research also set precedents for how market research can be conceived of as part of a wider marketing setting, and both disciplines as integrated in market making activities.

For the purpose of looking into market research, rather than into its role in a society where it exists, I rely on previous studies of marketing, and market research, as generative activities (Araujo 2007; Lezaun 2007; Schwarzkopf 2009, 2015), worthy of being taken on as having their own consistencies. I believe these consistencies are best approached as cultural. That means treating market research as subject to local systems of classification, meaning-making, technologies and conditions of production. This ties in to the market studies programme, where markets are framed as phenomena that shape and are shaped by social and technical arrangements and very much impacted by marketing and business thought (Araujo et al. 2010). To understand how markets are shaped by knowledge there is reason to unpack the knowledge production of market researchers. The study of consumption and markets is an important strand of research with which this thesis engages. For instance, industry affiliated ethnographers have pointed to the limitations of ideas of consumer segmentations' usefulness as a matter of representation of reality (Moisander and Valtonen 2006; Sunderland and Denny 2011). Studies into the history of marketing and how statements about consumers have been phrased have shown how such statements are part of the shaping of markets (Zwick et al. 2008). At times this 
has been framed in terms of performativity of marketing theory (Cochoy 1998; Kjellberg and Helgesson 2010; Mason et al. 2015). Cochoy has noted that in descriptions of markets, be they thought of as performative, governing or surveillance, customers and consumers are objects of use for marketers: drawing on what consumers are like is a part of establishing sales (see also Schleifer and DeSoucey 2015), for instance by promising the eventual usefulness of a market device in making a sale (Cochoy 2004).

This thesis relies on ethnographic description, which has previously been used to produce new interesting ideas about marketing knowledge and market research. Anthropologist Marianne E. Lien has studied Norwegian marketers, focusing among other things on how they phrase market situations as part of their work (Lien 1997). Lien has made the observation that consumers are assumed to be out there by markets but that her informants also believe that their knowledge about consumers is lacking (Lien 2004). Despite this knowledge gap marketers are adept at characterising customer segments in ways that align them with product categories, and they work to affect these ties (Lien 1997). Auto-ethnography has been employed to uncover the workings of market research projects from the inside (Grandclément and Gaglio 2011; Sunderland and Denny 2011). Ethnographic approaches help direct this inquiry by suggesting challenging the status of the consumer as an object of knowledge - urging for a pragmatic consideration of what it means to research it. Further, the study of market researchers who are tasked with addressing the knowledge preferences of marketers shows new ways of understanding such market knowledge.

The scholarly debate on market research has often approached it in ways that either seek to further develop or criticise such efforts. Alternative strands of scholarship have turned to the workings of market research. Such research has shown how market research activities are contributing to the enactment of its objects of knowledge. Advocacy of marketing research, or folding it into wider discussions on the role of marketing are of course useful for their own ends. However, both these positions risk leaving the workings of market research as a black box (Latour 1987). The study of marketing research as a set of generative practices, on the other hand, gives credence to how marketing research actually produces descriptions of markets and consumers.

As this thesis aims to understand how market research is undertaken, previous study into how market research is generative is very useful. In particular, attention to the practices of undertaking such research often actualises the role of client relationships and other relational concerns. This 
thesis seeks to further develop the relational nature of market research, while attending to the challenge posed by describing the practices and ideas of others. The ethnographic problem of describing what is already locally accounted for represents an area of study where the cultural aspect of market research is important. It is to this space for scholarly effort that I seek to contribute. 



\section{Theoretical Framework}

This thesis focuses on what market researchers say they do and how they do it. In this theory section I will motivate my choice to engage with market research as 'cultural' and why I am using ethnographic methods. Taking on this focus means approaching market researchers as reflective actors, with perspectives that tie together their practice and their conceptual understanding of research. Thinking about the epistemic as cultural also brings sensitivity to the social relations that permeate market research. It prompts me to outline what I mean with an interest in knowledge making; what it means to approach something as cultural, including a discussion of the culture concept and its limitations in this inquiry.

\section{On the 'epistemic'}

As previously noted I observe statements, materials and practices based on the assumptions of a cultural perspective on epistemic activities. With 'epistemic' I mean that which has to do with knowledge, after the Greek 'episteme'. Adding the Latin 'logos' (logical discourse and law-like organisation) suffix forms the noun 'epistemology' a more specific term for theorisation about the nature of knowledge. 'Epistemology' thus refers to the more explicitly structured ideas about the conditions for - and philosophical underpinnings of - knowing. Knowledge (the epistemic), and theorising about knowledge (epistemology) are overlapping but separable conceptual domains where the former encompasses the latter. This thesis studies epistemic phenomena including both epistemologies as well as other epistemic arrangements. I am interested in epistemic ideas and practices and believe that they may include things that are different from more prescriptive accounts of how market research ought to be done: often the purpose of formulating explicit epistemologies has to do with justification and setting goals for what constitutes sound research practices or knowledge claims.

Indeed, studies of knowledge have often come to stress the need not only to look to theorising, but also to how knowledge is performed. Things people do may be relevant for knowledge regardless of whether it is particularly theorised on. An example of how something may be epistemic while neglected in epistemology may be found with the circulation of papers in Latour and Woolgar (1979), or the caring for machines and samples in Knorr Cetina (1999). Such insights have led to steps away from the philosophy of science to more ethnographically grounded STS (cf. Sismondo 2011). Thinking about the epistemic as cultural is used to highlight how knowledge making happens in a specific setting. In studying this context, it is important to take into account not only overtly epistemological ideas, or results. Additionally, epistemically 
important phenomena include the mechanisms of knowledge production, such as the devices employed, the practices and the people who undertake the research.

\section{On the study of knowledge making}

The sciences are not a homogeneous system of thought and practice. Ethnographic studies into science in the making shows that they vary between situations and settings (Knorr Cetina 1999; Latour 1987; Latour and Woolgar 1979). Still, my informants and other market researchers draw on ideas of scientific rigour when they argue for the merit of their research. According to much market research literature and noted both in previous sections of this introduction and in Article 1 , the strength of this discipline lies in its ability to apply 'scientific principles' for the good of business (e.g. ESOMAR 2007). Given my interest in understanding market research as an activity worth exploring in its own right, rather than only as an example of scientific knowledge production, I think that it is important to maintain an open mind about what 'the scientific' really is. Indeed, a rigid definition of what science is in the context of market research is not relevant on the level of analytical framework, but is useful as an issue to study (Lynch 1997). My concern over a simplistic comparison with science stems from previous research into how the principles of the scientific are more complex than popular characterisations imply (Sismondo 2011).

As has been noted in ethnographic lab studies, the idea of the sciences as a collected way of being, that includes shared world view, use of tools, meanings and norms, poorly resembles the multitude of ways in which scientists do science. Karin Knorr Cetina argues that the sciences are not uniform, but fragmented into several different ways of being and doing. She referred to this difference in her seminal work Epistemic Cultures: How the Sciences Make Knowledge (Knorr Cetina 1999). She there argues that difference in ways of doing science can be understood in terms of culture. For example, high-energy physicists take care of their machines in ways which suggest that they are living entities and put focus on negative knowledge and sources of experimental error, while molecular biologists refer to living entities as devices and form positive knowledge based on their interaction with research materials (Knorr Cetina 1999). A cultural toolset can be taken to knowledge making by tracking the mechanisms established among research communities and groups.

\section{The cultural as a tool for inquiring into the epistemic}

This thesis takes an interest in the epistemic in the broad sense of the term. As such, it is neither merely an inquiry into epistemology nor the study of some monolithic form. The specificities of market research knowledge production as well as its richness beyond the purely theoretical ought to be taken into account. For this ethnographic endeavour, the tool that is to direct attention to 
multiple ways of thinking and doing is 'culture'. In the case of this thesis, it helps in focusing attention on how local interpretations matter. This point is specifically argued for in Article 1 where C-F Helgesson and I suggest the use of epistemography: the empirical study of (different) sets of epistemic ideas, local to the context where they take place. The term 'epistemography', which is borrowed from Lynch (2013) and Dear (2001), represents a call for a way of engaging with the social study of knowledge that does not diverge too far from ideas of it being a matter of locally justified beliefs. Otherwise there is a risk of losing sight of the local epistemic practices in the interest of a radical analysis of what it can mean to produce knowledge, ending up with explanations that do not engage with what they are to explain (Lynch 2013). There is reason to pay attention to views from within to catch aspects of the epistemic, which adjusts what counts as a new insight at the end of a study in the field examined, at least if working with this revelatory regime of ethnographic research.

Culture metaphors are useful for this study insofar as they present a number of points on which to focus. Knorr Cetina (1999) notes that epistemic work may be assessed as cultural in that there are many established ways of doing things within communities of knowledge makers. The application of the culture concept to epistemic work is a way to bring attention to how these machineries of knowledge production differ. The perspective is also useful because it allows for cross-cultural comparison, and thinking about what it means to use one set of epistemic tools such as the ethnographic ones employed in this thesis - on the ideas and practices of market researchers in relation to other research in the sciences as well as marketing.

Seeing culture in the materially broad sense may seem far from the meaning-oriented notion of culture proposed by anthropologists like Geertz (1973) and criticised by STS scholars (Latour 2005), but it is a perspective on the concept of culture that harks back to Victorian anthropologist Edward Tylor's 'complex whole which includes knowledge, belief, art, models, law custom, and any other capabilities and habits acquired by man as a member of society' (Tylor 1871: 1). While Tylor's notion of culture sets a singular standard of civilisation (and all the issues of ethnocentrism and colonial attitudes it incorporated) it nevertheless identified which phenomena that 'culture' may be said to encompass.

\section{Studying sense-making, practice and tools}

A cultural approach to knowledge making calls attention to how people involved see their situation, puts this in relation to the tools and institutions they have, while also acknowledging the environment where it happens (Knorr Cetina 1999). Such interest in sense-making in relation 
to material arrangements is not unique to those who eschew the notion of culture, but other metaphors such as economies or classification have been employed towards similar purposes. Drawing on Geertz, Traweek argues that ethnographic description involves a description of patterns of:

[E]xplanation and action, the meanings people bring from one situation to another, the connections and distinctions people make between certain actions, feeling, ideas, things, and their environment; these patterns make up a culture. (Traweek 1988: 8)

Similarly, Lorraine Daston points to this in her use of 'moral economy' to examine how scientific communities rely on balanced systems of ideas and values, making certain values, affects and assessment feasible and others unfeasible for knowledge making (Daston 1995). Knorr Cetina (1999) used a cultural perspective on the epistemic to focus her comparative study of researchers around the mechanics of finding knowledge in these respective environments. She assesses routines, technologies, epistemic considerations (that is, local ideas of what is going on), etc. Traweek (1988) notes that the cultural perspective allows for the use of several ethnographic themes that have been used when describing small-scale societies of classical anthropology (e.g. attention to ecology, social organisation, social reproduction, and cosmology), and assessing contemporary expert groups, in her case of high-energy physicists. Values, beliefs, artefacts and materials, and processes and interaction, all give detail to the explanation of human social existence (Traweek 1988).

Attention to local ideas is also inspirationally outlined in Bowker and Star's work on classification: ideas of categorising and sorting material create the reality in which people can act (Bowker and Star 2000). In the case of market research, examples in the articles included in this dissertation show that market researchers are very much involved in acts of sorting, and the making of vivid categories (see also Harrison and Kjellberg 2010). The purpose of categories like 'consumers', with labels dividing such figures into segments, are not necessarily about the effort to capture characters external to the research situation. Such a rendering would see market researchers as involved with representing reality as it 'really is'. Instead market researchers espouse different epistemic theories depending on situations and objectives.

A perspective that takes us closer to the practices of market research is to see how it establishes categories on which others, such as marketers, advertisers or other clients, may act. If categories are part of making markets then the ways in which they are consciously made in certain ways and not others could certainly benefit from asking how they could be different. The cultural and 
ethnographic perspectives on knowledge making and categorisation give rise to particular questions for this thesis on how the market research firm's research work is organised and what things are considered tools, objects of study, categories, outcomes or problems. This offers a way not only to a better description of market research processes but also for the potential of taking on market researchers' own techniques in our knowledge production.

\section{Limitations of the notion of culture}

An important but also problematic feature of the notion of 'culture' is that it is often used to motivate a holistic approach in relation to a distinct phenomenon ('a culture among other cultures'). 'Culture' describes difference by positing particular instances that hold together, and may be viewed as a whole and potentially be understood from within or from the outside. Describing interest in market research as cultural thus has particular effects on this inquiry. Franz Boas and anthropologists following him developed the culture concept to use it for speaking about plural ways of living rather than the aforementioned singular 'culture' of Tylor that encompassed most human achievement under the cultural banner. Boasian plural 'cultures' were not comparable on a spectrum of progress or civilisation, or racial or ethnic superiority but were traditions to be studied and understood in their own right, and through cross-cultural comparison (Monaghan and Just 2000).

If the cultural move is problematic as it presupposes the distinctness of difference, the notion is useful because it draws up a field positing that it is in some way particular and that it can be analysed as a whole. A snag of such a tool of designation, however, is that cultural boundaries are drawn according to what is recognised as distinct. In discussing how a related phenomenon: 'the field' as the place where anthropologists do their research is defined in anthropology, Akhil Gupta and James Ferguson lament that the notion of a site where a distinct culture may be studied is ultimately a construction largely left to common sense (Gupta and Ferguson 1997: 2) or enacted by anthropologists' narratives (Marcus 2006). The relative arbitrariness of where a cultural whole begins and ends is actualised by my fieldwork. In my case of Norna, the firm is a distinct place to which I needed to arrange access. It is a place to which I went and from where I left and where I now only return occasionally (cf. Gupta and Ferguson 1997). Further, Norna is a registered company and thus an entity recognised by law. However, Norna is studied through the instance of one of its departments (C\&T - consumption and technology), and the firm is part of a larger international group. Finally, I am using Norna as representative of something larger in this thesis: I want to use Norna as a case which relates to market research and commissioned knowledge production more generally. 
Instead, I suggest that 'culture' might be a way to approach knowledge making as cultural rather than positing that it constitutes a culture. The former interpretation is more of use to this thesis, as the latter carries with it many problems of demarcation: it is mostly important for my inquiry to have a way to think about humans, their ideas, tools, environment and practices as connected. I do not seek a way to separate what market researchers do in opposition to 'proper' or 'real' researchers (a recurring phrasing by my informants at Norna when they relate to what they consider as actual science) or determine what would constitute 'non-epistemic' cultures. This thesis sees market research as a distinct (though far from rigid) form. Further I consider the analysis of industry accounts and fieldwork at particular sites as useful cases for understanding it. Nevertheless, it is because of the weakness of the notion of cultures as self-contained entities out there that I stress that approaching phenomena as cultural acknowledges the interconnectedness of issues (Gupta and Ferguson 1997). Research problems involving situated people, environments and tools should be studied in a manner where explicit ideas (e.g. texts written by and for market researchers; internal and external presentations), practices (e.g. research, recruiting, conducting meetings), underlying forms (e.g. norms), environments (e.g. Norna's offices) and materials (e.g. forms, research stimuli) are all given weight.

\section{Implications of theoretical tools in analysis}

By framing certain things as cultural, new questions can be asked about why designs, materials, routines and results are the way they are, without resorting to ad hoc assumptions of functionalism. Indeed, the culture concept is interesting as a way of discussing and comparing different ways of being and doing things. Either this difference can be potential: it could be otherwise' (Woolgar and Lezaun 2013) or it could be a statement of fact, as when the seemingly simple and straightforward is shown to be far from determined, but the result of particular decisions, or shared forms.

If a problem of 'culture' is that the label is applied to something already distinct, and that branding culture 'technological' or 'epistemic' assumes distinctness beyond what may be necessary for a given analysis, it makes sense to think about how to use culture in an epistemic setting that is ambivalent about if or when it is about knowledge making. The thesis strives to avoid ideas of market research - and its success and failures - as matters of falling short of applying 'science'. Although this shortcoming and its relevance is noted to be discussed by market researchers (see Article 1 for a brief mention of this) and my informants, I opt to treat such distinctions as part of the topic of study rather than as an analytic description (Rappert 2001). The articles and this introduction are more interested in how market research actually 
integrates concerns over signing and pleasing customers with epistemic sense-making and work execution. By focusing on my informants' point of view, as well as other industry actors' ideas on the topic - issues of what market research is about may be deferred to the informants who have often pondered these issues for longer than I have.

The actors whose views and practise I take so much interest in across the articles contributing to this thesis remain somewhat distant in the ethnography. This can be considered as an oversight; I could for instance have made a study of how one becomes a market researcher. Such an approach would have been in line with Traweeks's interest in social regeneration (Traweek 1988). However, given my research interests, it is the outlook of my informants on the processes, tools and relationships that their work entails that is most important. For example, even if I pursued questions about the people involved I have seen little sign of a strong community of market research with a clear market researcher role to fill, accessible for study. Looking for a robust market researcher role and its regeneration in this study would not produce a well-defined category such as the physicist (Knorr Cetina 1999; Traweek 1988) but rather end up with the conclusion that what makes a market researcher is rather nebulous.

Taking local thought seriously is important for academic theorising about knowledge. Indeed, it is something that is necessary for understanding a cultural setting. It allows for thinking about how a group of others interpret the meaning of knowing and researching. It provides a distinct take on how pragmatic knowledge concerns are expressed in a setting that strives for preparing for decision making. Connecting knowledge and doing, a common concern within discourses of performativity, may be further opened up through the study of different cultural settings. Thinking with market researchers' theorising offers the chance to ponder the relationship between concerns over strategy (such as commercial pressures) and concerns over description.

An important part of the culture concept, which has motivated its use and change over time, has been the interest in difference. By acknowledging that there is a view from within which has validity of its own, and which may be gleaned from an outside point of view, understanding of a social setting cannot ignore local ideas without losing out on an important perspective. With local interpretation available to us in ethnographic inquiry, anthropologists may experiment with their own knowledge making, taking on the tricks employed by studied informants. In the case of this thesis I will be involved with how market researchers make and convey research to inform recipients. In turn, I used survey questions and call for summarising them to provoke reflection 
on the earlier section on why study market research. I further attempt the use of evocative quotes and summaries. Such techniques are used by market researchers and other knowledge producers to make the product as engaging and persuasive as possible.

Finally, by thinking about market research as an achievement within a business setting, this thesis (particularly Article 4) offers alternatives ways to think about the social effects of knowledge making in ways that may address a performativity discourse (Callon 1998; MacKenzie et al. 2007) that has avoided getting tangled in local interpretation. This is particularly argued for in Article 1 and in the thesis discussion. The messy field of market research, studied as a cultural setting, rich with not only tools, practices and specific environments, but theorising and understandings, may offer opportunities for a new discussion of performative, constructive and pragmatic notions of knowledge making. 


\section{Methods and Engagement: ESOMAR, Norna and Researching Researchers}

My informants have noted the long timeframe of my project with extended processes of collecting material, analysing and writing up my study. They attributed the amount of time I have put towards the project to a concern over a scientific standard that market research cannot compete with. Indeed, my informants sometimes denigrated what they do in comparison with their idea of a scientific approach. In part, I believe that this is most fruitfully interpreted as a courtesy to me. To some extent, this appeal to science is also a way to claim high standards for doing market research. One of the reasons why I gained access to Norna was that my informants felt that the study would be a beneficial influence on the firm's work. It would strengthen the company's 'connection to academic research'. While I do hope that my research will be of some interest to my informants, I am left uneasy with the idea that market research does the same thing as science, but only less well so. There are two general problems with such a view. First, it reproduces an unfortunate hierarchy between the academy and other knowledge approaches, one that overlooks how knowledge aims may very well be different. Second, it assumes a uniformity of the sciences, deeply problematic given this thesis' grounding in ethnographic attention to knowledge making.

This section will outline my involvement with ESOMAR literature and doing interviews and participant observation at Norna. As the primary field site, Norna will also be given a brief outline to convey some context to this ethnographic engagement. I will discuss my work in relation to the work that market researchers do. This discussion provides an account of how I view my contribution in relation to notions of critical research, unpacking issues, etc. Further, I will discuss my own process of writing ethnography in the form of articles in a compilation thesis.

\section{Studying market research epistemics in ESOMAR literature}

As a way of preparing for interviews and participant observation at Norna, as well as to home in on how market research could be fruitfully assessed, I studied material about market research published by industry organisation ESOMAR. Similar to many ethnographic projects, fieldwork thus started at the desk (Monaghan and Just 2000). It allowed me to begin thinking about my work, while sinking my teeth into some actual material. It also helped provide a 'received view' beyond marketing literature (Belk et al. 2012; Kotler et al. 2016) with which to further engage, establishing what market researchers may think that it is that they do. Given my interest in looking at a phenomenon that I understand to be cultural, getting an idea about what explicit 
beliefs this cultural field contains is very useful. The resulting article (Article 1 in this thesis) was written for a special issue on performativity in marketing in Journal of Marketing Management. It allowed the positioning of this inquiry in relation to the interest in market studies to extend the notion of performativity from the organisation of financial markets to the theories and processes of marketing. Finally, the desk review offered material to discuss with my informants. Having something in the works would come up in conversation, and during the period when Helgesson and I revised the article for publication, I had the chance to consider my writing in light of what I saw during fieldwork.

ESOMAR is a prominent international organisation for market researchers (ESOMAR: 'About us', available at https://www.esomar.org/what-we-do/about-us, accessed 23 Jan 2018), and it is the only international organisation that my informants related their work to. As their regulations and ethical policies set the standard for many firms (compliance with ESOMAR standards is often stated as a token of responsibility by market research firms) I used material published by the organisation to gain what I would regard as fairly uncontroversial and accepted statements about what market research is, and what sort of knowledge it provides. The handbooks were assessed for discussions about the purpose and epistemics of market research, and relevant sections were then thematically coded (Saldana 2012).

The ESOMAR material is different from the subsequent research material that was generated through extended time in a specific site. The connection between the two is of that between a local and a large - if not global - scale. ESOMAR handbooks express epistemological statements in a wider context than that offered by my fieldwork at Norna, dealing with multiple national markets, and several kinds of market research. At the same time the ESOMAR context is narrower: writing a book means an editorial process and exclusion of lots of detail, work, comments, etc. Statements in a handbook have gone through thorough processes of writing and editorial revision (Moisander and Valtonen 2006), and for different purposes than statements given to colleagues or a pestering ethnographer. For both these reasons, the handbooks give a complementary perspective to those expressed by my informants. To some extent, it is material with tenuous connection to that derived from participant observation. That said however, contemporary anthropology often situates local studies within larger contexts (cf. Hylland Eriksen 2001; Lindquist 2009). It also bears mentioning that the ESOMAR handbooks do not convey a set of radically different statements from those I observed at Norna: the statements 
assessed in Article 1 are similar to what my informants would express and do during fieldwork, outlined in Articles 2-4.

\section{About Norna}

The participant observation part of my fieldwork consisted of following the work at a firm I have opted to refer to as Norna. My fieldwork happening at Norna in particular was largely the result of circumstance. Through an academic contact I learned that Norna, which I knew by name as a large and well-established firm, had a tradition of interest in academic research. Maybe they were open to discussing market research with a field-working academic. After an introductory interview with 'Edward', the person who would become my primary informant and a few meetings with other co-workers and a local manager, I was let in at the level of one of the firm's departments in Stockholm.

In terms of spatial organisation, Norna occupies two floors in the building where the firms' head office is located. Branches of the firm exist in several Swedish cities, including the firm's departments for respondent recruitment, programming online surveys, and facilities for CATI (computer assisted telephone interviewing, a marketing term for the setting up of a contemporary call centre). When I first came to Norna I was struck by the multitude of meeting rooms, many of them small enough to hold only two to four people, with some rooms being larger conference rooms. These rooms are windowed, with either clear or frosted glass, and interior decoration is largely minimal with lots of sleek white surfaces. The offices are spacious, with co-workers free to use unreserved rooms for meetings, phone calls or chats. The open office landscape, with large windows and the frequency of glass doors and interior windows conveys not only a stylish modernity, but also the impression of transparency: it is possible for an observer to glimpse the range of work being done without getting exposed to undue detail. Gaining an overview is not always so easy however, and the generic look of meeting rooms and near-identical desk clusters makes it easy to get lost.

Co-workers from different departments interact during lunch hours and afternoon coffee breaks. During these the lunch room as well as the lobby become filled with Norna co-workers. As Norna employs a large staff organised into multiple departments, and I primarily followed one group, I never reached the point where I could fully make out if a new face belonged to someone recently arrived, a temporary guest or if I had simply met another seasoned Norna co-worker for the first time. After a few months in the Norna offices, I began to notice that the non-committal nods and hellos had extended to include me in this relatively anonymous community of office 
dwellers. Over lunch or by the coffee machine I was regularly asked which department I was in. This is not to say that I managed to become an insider among a tight-knit group, but rather expresses the somewhat transient nature of a place like Norna.

Norna is part of a larger international marketing group, which includes advertising and marketing firms, embedding the firm not only in an international organisation, but also in a larger marketing context. The company itself contains several different departments that cover different market sectors as well as functions such as 'Operations' which programmes and sends out surveys, undertakes CATI work, etc. The department that I followed deals with clients in fast-moving consumer goods and other consumer facing services such as consumer banking and IT. I refer to this department as Consumption and Technology (C\&T). C\&T consists of a little over 20 coworkers. Staffing is quite fluid and multiple employees joined and left the firm during my fieldwork and while I wrote this thesis. The department features a few groups united under joint management: the qual team, the account managers, the project managers and the assistant staff. Account managers are specialised according to type of client they cater to (at times managers introduced themselves to me as working primarily with for instance fast-moving consumer goods or banking and financial services), while the qual team consists of specialists in qualitative methods.

\section{Co-workers and roles at Norna}

Norna distributes responsibilities in projects according to employee roles (see Figure 1). For the purpose of explaining research projects, two categories of co-workers are particularly important: project managers and account managers. Much work is done according to other demarcations: for instance, there are administrative and management positions beyond these two categories. However, managers at $C \& T$ retain account responsibilities together with other account managers, and administrative staff are in several cases included in meetings for project managers. The distinction between managing accounts and managing projects can thus be referred to as one that runs through much of the work at C\&T: The connection between managing accounts, being responsible for signing clients and selling projects, and making sure that the projects run as they should is fundamental for successful research. The division of labour in market research work actualises the conditions of commissioned knowledge production, in that concerns over sales and marketing and knowledge making are both separate and considered in tandem. Market research relies on having commissioning clients, and producing knowledge for them. While handbooks in market research methodology mention the role of appealing to clients and what they need (Belk et al. 2012; Moisander and Valtonen 2006) the emphasis tends to be placed on how to do the 
research. The sale of market research is not as prevalent but would conceivably be marketed on the same principles as any good (Kotler et al. 2016). Sales as well as project execution are both crucial aspects of being in the market research business.

Although projects are team efforts and many responsibilities overlap, there are differences in who is primarily responsible for what, as well as hierarchical differences in seniority. In terms of hierarchy, the role of account manager is a step up. It is a position that is emically described as attained through seniority, experience and motivation. Account managers staff the projects they sell with a partner project manager as well as additional staff such as an expert in qualitative methods (if the project should need one). The project manager is responsible for running the project and is expected to log their hours to paying projects as much as possible. In terms of execution it is the project manager who has primary responsibility for dealing with Operations. This is the external department of programmers ('operators'), telephone interviewers and recruiters who deal with data entry and quantitative collection, primarily via Norna's online respondent panels as well as by call centres.

Secondary roles within C\&T besides the aforementioned managerial responsibilities of some account managers include an administrative assistant and a cadre of experts in qualitative methods. The 'qual group' consists of a group of senior experts in qualitative methods, who both manage their own clients (doing the work of account managers) and perform qualitative research (work which overlaps the analytical and organisational responsibilities of project managers). The qual group also has a few of their own project managers who deal with the execution of purely qualitative projects.

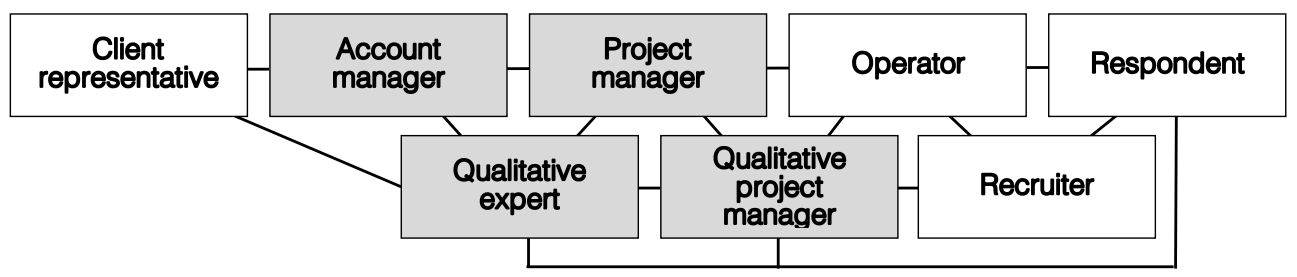

Figure 1 Organisation of possible actors involved in a market research project

Note: My informants all ranked in the roles coloured grey

Source: Author's illustration, based on division of roles at Norna

The staff at C\&T became familiar to me over time: I would greet and speak to most of them (if only for short greetings on first meeting during the day and then nods for subsequent encounters in hallways) during the day's work meetings, coffee or lunch breaks. Socially, C\&T was relatively 
homogeneous: the staff consisted of native Swedes and the odd Northern European expatriate. With the exception of an older assistant the full group had tertiary education, with a few coworkers holding postgraduate degrees. As this study deals with knowledge, the educational makeup of primarily business and marketing among C\&T co-workers training is made more central than other social classifications. I do see how a study along the lines of class, ethnicity, gender, etc. is certainly possible - the make-up of the researchers is far from a representative sample of the Swedish population. There would be room for a critical engagement with issues of equality, representation or the power dynamics of marketing. The working conditions of market research settings, featuring plenty of overtime and many stressful projects constitute another important road not taken here. While interesting, such lines of inquiry fall beyond the scope of this thesis. For the purpose of this study - a pragmatic exploration of market research as commissioned knowledge making - comparison along educational lines is the most relevant.

Examples of the role of educational background within C\&T include the particular expertise of the statistician in the group, or the experts in qualitative methods who held degrees in psychology, were licensed therapists or had taken psychology classes at university. Eric, an expert in qualitative methods had teaching experience and academic publications on the subject of consumer research. These people would have (or at least were able to claim) authority on particular interpretations and work processes. Common educational backgrounds involved studies in business and management or social sciences. Several employees also expressed interest in psychology and a few of the business majors had taken university courses on the subject. Not only were such differences thought to be relevant by my informants but education appeared to add to formal positions in contextualising different opinions about market research activity at Norna. For example, researchers trained in psychology would draw on psychodynamic notions of what constituted a research subject while the statistician would express qualms over the validity of researching them.

\section{Names, naming and anonymity}

I am unsure of how this research project is going to affect those I research: As I am neither interested in becoming a mouthpiece for my informants, nor wanting to do anything to hurt them, is why I decided from the outset to render them and the firm anonymous in publication. My decision to use the moniker 'Norna' stems from a range of associations I have with the name. First, the name suggests the geography of Norna as located in the Nordic region. Further, Norna happens to be a name for the orchid Calypso bulbosa, native to Sweden. I also like the connotations the name has with the Norns ("norna/nornor' in Swedish) of Norse myth: mysterious 
women who weave the threads of fate. The task of weaving fate reminds me of my informants, who interpret the world or produce the opportunity to act on it. Ultimately however, I have chosen Norna for a more straightforward reason: the name is easy to remember and it is short enough to read well even when repeated over the course of a full thesis. Some terms for the Norna organisation have also been altered, so that I refer to company groups and work titles with names that may differ from how Norna translates them into English. As Sweden has only a handful of large market research firms this measure is also taken to make the company less easy to identify.

All the named Norna researchers in the article and introduction have been assigned aliases. I want to avoid a situation where my informants get singled out among their peers for what they have said to me and I have little right to interfere with my informants' careers or work status. My informants have afforded me trust in letting me hang around, observe and ask questions. I did not ask to study their personal lives and such details would not add much understanding to the topic of this thesis. For these reasons I have anonymised my informants by using pseudonyms or avoiding names altogether - in the articles (Davies 2012). It is worth mentioning that such practices have parallels in the market research world which I have studied: aliases and personas are regularly used in order to anonymise respondents, as well as simplifying the range of respondent responses to help readers take in a full picture. For the sake of clarity for the reader I have used a general naming convention in picking monikers: all Norna staff who have account manager status have names beginning with an A (e.g. Andrea; Aaron), those who are project managers have assigned names beginning with P (e.g. Pia; Philippa) and the experts in qualitative methods have names beginning with an $\mathrm{E}$ (e.g. Eric; Eve).

As I believe in keeping an ongoing discussion with informants when possible, I have shared drafts of my work based at Norna with C\&T co-workers and offered staff the opportunity to review interview transcripts. I have primarily done so to ensure I have not made mistakes in my characterisation of what went on during my time at Norna, but also in order to get the chance for input regarding my interpretations. My informants have only occasionally given me feedback on the texts I have shared. Apart from short comments on drafts, I have received particular comments mainly on things I have brought to my informants during presentations or mentioned in conversation. The only requests for specific materials I have received were a summary of desired respondent traits (see Article 2), and my preliminary aims as I presented them at the onset 
of fieldwork. In both these instances, individual researchers who found the materials to be of personal interest or use to them, asked me to email them copies.

\section{Fieldwork at Norna}

I started doing initial interviews with a few Norna employees in the autumn of 2013 and expanded my engagement in January 2014. During this time, I also negotiated access to the firm, and interviews became a way for me to get to know Norna, and for its co-workers to get to know my intentions. This led to increased participation and fieldwork at Norna from February to June 2014. Research material was primarily produced through taking notes and conducting interviews. Notes were produced through continuous entries in a notebook that I carried around during fieldwork. This notebook both enabled and got in the way of fieldwork. It gave me something to do with my hands, allowed me to keep myself occupied at times when I was listening in on meetings, and was a great help in remembering the day for my research diary. On the other hand, my using it clearly signalled to my informants when I thought that something was of interest, or worthy of caption. This selection is not readily separable from subsequent acts of coding on my part (Saldana 2012) but locates part of what would be considered analysis within the fieldwork phase (Davies 2012; Latour 2005).

My informants would regularly joke about my note taking during meetings, and indicate my use of the black Moleskin as my de facto work. I think this is quite observant on their part: my informants revealed how much of my thinking happened in that note-taking process. As a central part of my research routine I did a debriefing of the research diary as regularly as I could (Davies 2012; Moisander and Valtonen 2006). Most often this would mean that I took the time to make entries in a text document where I wrote down what had transpired during a day or situation, what it reminded me of and how I thought it relevant or connected to other things in my field. Typically, this would allow for completing thoughts or entries only partially entered into my notebook. The research diary ended up spanning 53,299 words (or 172 pages of double-spaced text), with entries for 58 days of fieldwork and is both an important source of information and a crucial step in my analytical process. It is because I have put much of myself into it that it has been most centrally useful in the subsequent process of thinking and writing about my field.

\section{Participation in projects}

An important way in which I participated in the day-to-day work at Norna was through taking part in research projects that went on as I was there (see Table 1). I was involved to a varying degree in the different projects. In some, like the bank card project which features in Article 3, I was sitting in on set-up meetings with the client and took an active part in doing interviews, 
summarising results and making the presentation. In other projects, like the drink testing, I helped out with running the focus group; pouring drinks, making sure the client was comfortable in their remote viewing room, taking notes during the analysis meetings, etc. Often, I could be useful by proofreading materials, which was a way for me to be participating in projects where I had come in late but sought to get a feel for what was going on. Some projects, such as the TVtesting focus groups, were only accessible to me as presentations that I read and as the topic of particular interviews.

I did not participate in any project from its first sales meeting to a final client presentation. There are a few reasons for this. First, my informants would offer me the chance to participate in projects only when they knew what they were about, meaning that some work was already done. At the point where I could be included my informants would have sold the project to a client and have an idea about how the project was running. Early stages of negotiation and set-up with the client were therefore difficult for me to observe in person. Further, my informants were loath to bring an unfamiliar face to a final presentation. Therefore, I have been more directly involved in the parts of the projects where research and analysis was undertaken, and less in the early and final parts of a project, where client interaction takes prominence. My way of amending this is through the making of a bricolage (cf. Lévi-Strauss 1966) - or composite picture - of what a project tends to involve; this features in Article 3. I have also related to the kind of standardised project models that are employed at Norna and elsewhere (see Article 3). To get a better idea of what went on during client contacts, I made sure to interview informants about their preparations beforehand. This allowed me to take on the role of test audience for my informants to try out their presentations. I would also conduct post-presentation interviews in a few cases. Notably, I followed up the active wear project and the TV-testing projects in this manner. These interviews informed Article 3, and meant a lot for my conception of client relations in Article 4.

Besides the research material that I generated by participating, observing, writing and interviewing during my fieldwork, I assessed documents from Norna. Documents include texts and images from the research projects in which I took part (see Table 1), including project presentations. I also collected work documents, internal training materials, and forms. These documents have been important in understanding certain aspects of market research work, such as in the case of recruitment memos. At other times, they have been assessed for analysing the forms and ideas of research result presentations - useful comparison to what is said in interviews or noted in the field diary. 
Table 1 Summary of research projects observed during fieldwork

\begin{tabular}{|c|c|c|}
\hline Project & Type & My involvement \\
\hline Active wear & $\begin{array}{l}\text { Qualitative and quantitative } \\
\text { testing of brand image. } \\
\text { International online } \\
\text { quantitative survey and online } \\
\text { focus groups }\end{array}$ & $\begin{array}{l}\text { Participation in project } \\
\text { meetings } \\
\text { Debriefing interviews after } \\
\text { presentation } \\
\text { Proofreading presentation } \\
\text { Work documents collected }\end{array}$ \\
\hline Bank card project & $\begin{array}{l}\text { Face-to-face qualitative } \\
\text { interviews }\end{array}$ & $\begin{array}{l}\text { Participation in client meeting } \\
\text { Participation in project, } \\
\text { including translating and } \\
\text { developing interview guide, } \\
\text { undertaking and analysing } \\
\text { interviews and making the } \\
\text { presentation } \\
\text { Work documents collected }\end{array}$ \\
\hline Bank PR study & Online quantitative survey & $\begin{array}{l}\text { Participation in summarising } \\
\text { results for analysis as well as } \\
\text { in making tables and figures } \\
\text { Work documents collected }\end{array}$ \\
\hline $\begin{array}{l}\text { Construction company PR } \\
\text { study }\end{array}$ & Online quantitative survey & $\begin{array}{l}\text { Interviewing project manager } \\
\text { Work documents collected }\end{array}$ \\
\hline $\begin{array}{l}\text { Insurance company customer } \\
\text { survey }\end{array}$ & Online quantitative survey & $\begin{array}{l}\text { Participation in start-up } \\
\text { project meeting }\end{array}$ \\
\hline Probiotic drink testing & $\begin{array}{l}\text { Product testing (tasting and } \\
\text { concept testing) in focus } \\
\text { group form }\end{array}$ & $\begin{array}{l}\text { Participation in project } \\
\text { meetings } \\
\text { Participation in analysis and } \\
\text { production of presentation } \\
\text { Work documents collected }\end{array}$ \\
\hline TV concept testing & Focus groups & $\begin{array}{l}\text { Interview with project } \\
\text { manager }\end{array}$ \\
\hline TV programming test & Focus groups & $\begin{array}{l}\text { Interviews with project } \\
\text { manager } \\
\text { Sitting in as test audience for } \\
\text { rehearsal of presentation }\end{array}$ \\
\hline
\end{tabular}

Source: Author's observations 


\section{Conducting interviews}

Interviews have played an important part in gathering materials for this study. A total of 28 interviews (see Table 2), ranging from about half an hour to two hours in length, were recorded and transcribed, resulting in roughly 511 double-spaced pages of text. My very first interview was not recorded and only summarised in the research diary from memory. Only one-on-one conversations were recorded and I relied on notes and memory for documenting conversations as they took place during meetings, etc. After interviews and conversations, I often sat down by my assigned desk and did a quick entry into my fieldwork diary to be sure to write from fresh memory. The interviews allowed me to straighten out details, and assess individual opinion on discussions, themes emerging during meetings, conversations and other fieldwork situations. Some of the reflection that I am interested in was performed during interviews as my informants made sense of their work, in response to my questions. Thus, to some extent the reflections were prompted by me. I do not regard this as a problem, but I have attempted to convey my own role in producing reflexive accounts in the articles, just as I point out how my informants' framing of their encounters with respondents have particular effects (see Article 2). Beyond this role as one of reflection for me and my informants, interviews were a source of input for understanding what I witnessed: I could ask for pointers as to what I had seen, what something meant, or straighten out minor details. To the extent that facts were sought, I noticed few conflicting accounts between interviews and other observations. This is not to say that I have triangulated sources (cf. Canniford and Shankar 2012), but I found the documents of a project, my notes of it, and the information I gleaned from interviewing informants about it to be relatively aligned. 
Table 2 List of interviews

\begin{tabular}{|c|c|c|c|}
\hline No & Date & Informant's role & Topic \\
\hline 1 & 20130823 & Expert in qualitative methods & General interview; field access \\
\hline 2 & 20130829 & Expert in qualitative methods & General interview \\
\hline 3 & 20140127 & Project manager & General interview \\
\hline 4 & 20140129 & Project manager & General interview \\
\hline 5 & 20140129 & Project manager, statistician & General interview \\
\hline 6 & 20140131 & Project assistant & General interview \\
\hline 7 & 20140131 & Project manager & General interview \\
\hline 8 & 20140131 & Project manager & General interview \\
\hline 9 & 20140207 & Project manager & General interview \\
\hline 10 & 20140207 & Expert in qualitative methods & General interview \\
\hline 11 & 20140226 & Account manager & General interview \\
\hline 12 & 20140305 & Expert in qualitative methods & Screening procedures \\
\hline 13 & 20140324 & Project manager & General interview \\
\hline 14 & 20140327 & Project manager & General interview; TV concept testing \\
\hline 15 & 20140410 & Account manager & General interview \\
\hline 16 & 20140422 & Account manager & General interview \\
\hline 17 & 20140424 & Account manager, team leader & General interview \\
\hline 18 & 20140505 & Account manager & General interview \\
\hline 19 & 20140512 & Account manager & General interview \\
\hline 20 & 20140514 & Account manager, team leader & General interview \\
\hline 21 & 20140519 & Account manager & General interview \\
\hline 22 & 20140523 & $\begin{array}{l}\text { Expert in qualitative methods, team } \\
\text { leader }\end{array}$ & General interview \\
\hline 23 & 20140602 & Account manager, team leader & General interview \\
\hline 24 & 20140617 & Project manager & Active wear project \\
\hline 25 & 20140617 & Expert in qualitative methods & Active wear project \\
\hline 26 & 20140617 & Expert in qualitative methods & Television programming testing \\
\hline 27 & 20140619 & Expert in qualitative methods & $\begin{array}{l}\text { Active wear project; } \text { Television } \\
\text { programming testing }\end{array}$ \\
\hline 28 & 20140623 & Project manager & General interview \\
\hline
\end{tabular}

Source: Author's field diary 


\section{Access to the work at Norna}

During my time at Norna I had access to the physical premises, and during office hours I could come and go as I pleased. I also had an assigned desk at C\&T. In effect, I was assigned an unoccupied desk space and I was moved a few times with shifted seating for C\&T employees. I was invited to most meetings gathering the full department and to the meetings of the qualitative research group. I also attended the meetings of the projects in which I took part. Though I had very good access to the physical locales, allowing me to watch and listen to the daily activities of the open office landscape and the work that happened in meeting rooms, I lacked access to some parts of local activity. As I could not access Norna's intranet and was not added to work email lists, I would only receive information actively shared with me by someone alerting me or forwarding me emails and attachments. My informants were very generous with sharing work materials, and would notify me when they noticed a meeting or activity that they thought would be of interest to me. However, I could not stumble upon interesting things in emails and documents, as I may have been able to with more extensive IT access.

\section{Time in the field}

While extended fieldwork is sometimes thought of as a criterion for ethnographic quality, there is reason to consider the characteristics of the project to interpret length of time in the field. Traweek has been useful to consider as she calls attention to thinking about engagement of fieldwork and its duration (Traweek 1988). Relating to the common anthropological assumption that participant observation ought to cover the span of a year, which was established by the ground-breaking ethnographic work of Malinowski during the First World War (Malinowski 1961), and criticised as ad hoc and arbitrary (e.g. Gupta and Ferguson 1997), she argues for the need to keep fieldwork long enough to understand the local cycle of activity. This is interesting in relation to market research as such work suggests a different cycle. Traweek's idea is that the merit of doing fieldwork for at least a year allows for traditional society undergoing its seasonal cycle. To her, this has meant that it is important to follow high-energy physics projects on and off for several years, as projects go on for extended periods. In my case it means the opposite: market research cycles are much shorter. While the business year certainly affects my community as a whole, the primary cycle of market research as an effort to produce accounts about markets and consumers is that of the individual project, and the steps from selling a project to presenting results seldom takes more than a month or two. It is this sequence that sets the pace, and the conditions, for market research activity. 


\section{Focusing on 'qual' over 'quant' and senior managers over junior managers}

In early discussions about access and my research interest, the manager and senior staff who constituted my gatekeeping informants (Davies 2012) at Norna asked me about what I was interested in, regarding types of clients and methods. At the time, I was interested in keeping my observations as open as possible, especially regarding qualitative and quantitative methods. Although I mentioned that my own expertise lies more in qualitative analysis and methods I asked to be involved with both types of projects.

As market research is characterised by relying both on qualitative and quantitative ways of generating and analysing materials, a clarification might be made to explain why this thesis covers qualitative analysis more carefully. While this division may appear overly rigid and somewhat arbitrary (Belk et al. 2012), many employees with Norna would position themselves in terms of preference or familiarity with either 'quant' or 'qual'. If looking at marketing thought of as a cultural field, we do well to remember the central role of motivational science (established after the Second World War by Dichter as a way of gaining insight into the consumer) to the way both marketing and market research looks today (Berghoff et al. 2012). Even as quantitative research has risen in importance, and a contemporary discourse of 'big data' has established the ambition for quantitative analysis without the need for theory (Anderson 2008), consumers are still conceived of through a lens of motivational science, psychodynamic theories (Belk et al. 2012) combined with ethnographic approaches (Moisander and Valtonen 2006) - what my informants would regard as 'qual'.

During fieldwork, I gradually became more and more involved in qualitative research projects. The use of qualitative methods, of which I am more knowledgeable, allowed me to be of more use in the projects, leading to richer materials, as I could see more, and ask more initiated questions, prompting further expressions and accounting on the part of my informants. A sideeffect of this is that most of the projects that are discussed in the articles are qualitative, and many quotes come from informants who are experts in qualitative methods or account managers who tend to work on qualitative projects.

Another tendency in this material that is evident to the reader of this thesis is that senior staff have more voice than junior employees. There are relatively few quotes from the project managers, while account managers and experts in qualitative methods feature quite frequently in some of the articles (especially Articles 2 and 3 in the case of experts in qualitative methods, and 
Articles 3 and 4 in the case of account managers). This is not a feature that is unique to this particular ethnography - much classic anthropological fieldwork has dealt with the accounts of elders and chiefs over the perspectives of other people such as younger women or children (Hylland Eriksen 2001). What senior staff tended to provide, however, were reflections on client relations and dealing directly with respondents. Both these phenomena are vitally important to this thesis, yet such contacts are the purview of the senior staff. A study featuring the perspectives of project managers may have focused more on intradepartmental relationships, and the pressures of the production cycle. It will not be here.

\section{My engagement with informants}

I have sought to understand my informants, and what they think about their objects of knowledge, partly motivated by the interest in knowledge that exists in the academy. Rather than setting out to criticise, I believe that my work can be said to focus on the critical competence of actors (Callon 2005; Latour 2005). That said, I do not believe that it will be difficult to see the difference between my own assertions and those that I ascribe to my informants. I have merely thought more in terms of assessing insiders' perspectives for the purpose of understanding, rather than particularly focusing on exposing or criticising. It is my firm belief that careful ethnographic attention to market research is destabilising both to its champions and vehement detractors.

This may mean I have acted differently from how my informants hoped. As I argue in this thesis, their idea of scientific work is one of alignment between client relationships, usefulness and scientific rigour. Though I do not doubt that new useful questions may arise among my informants when they read my material, they may find that my questions do not lead to immediate action to improve market research activity. In this sense, my work is more useful for an academic readership that may be more satisfied with the questions as they are posed and answered. As I have nevertheless worked to maintain reciprocity, I have attempted to be of use during my fieldwork: when sitting in on meetings I often provided notes (I was taking notes anyway), and during analysis sessions I would take down findings summarising them for the group I was listening in to. I helped out doing interviews in the bank card project, and in sitting with the client observing focus groups during the drink testing. As I had offered to give a second opinion on what I saw during research projects I took part in giving my impressions and interpretations of common themes in interviews and focus groups I observed. I have also proofread, summarised and translated presentation material. 


\section{Myself in relation to market research as a field}

A staple in ethnographic texts deals with how the researcher positions him/herself to those that they study (Davies 2012). Commonly, anthropologists have dealt with studying people unlike themselves, for a readership that has more in common with the anthropologist than the studied informants (Gupta and Ferguson 1997; Monaghan and Just 2000). The asymmetries that have tended to characterise the relationship between researchers and the people they study have been thoroughly criticised (e.g. Clifford and Marcus 1986). As anthropological studies have moved away from the norm of a privileged researcher studying less privileged, 'othered' people, approaches have included studying up or sideways (Hannerz 2006). Alternatives to this model have also included ethnographers emerging from groups traditionally subjected to study (Spencer and Barnard 2002) and their dynamic is partly offset by ethnographers doing 'ethnography at home' (Hylland Eriksen 2001). This notion of insider ethnographers has been suggested to have a more initialised viewpoint and a less objectifying ethnographic eye. While this thesis is one that does not go into power dynamics, or indeed, much of the analysis of critical approaches, the notion of doing ethnography at home, or as an insider is a relevant one for my engagement with the market research field and Norna.

This study has been ethnography at home in a few different ways. First, I have undertaken fieldwork in my home town among people who like me are largely Swedes with tertiary education. More importantly, however, is my own experience of doing market research. After finishing my masters degree and before beginning my $\mathrm{PhD}$ training I worked for a year and a half in 2011 and 2012 at a consultancy firm as an analyst. My work with the firm dealt mostly with commercial research projects, ranging from purely market research-oriented focus groups, to desk research, as well as conducting and writing more ethnographic reports. My time doing this form of commercial research gave rise to my interest in researching the topic of knowledge making meant to inform action, as I repeatedly found myself asking questions about the nature and ends of commission-based research in a commercial context. It has also meant that I had some initial bearings on what market research was, when setting up the study.

Anthropologists writing about doing fieldwork have often come back to how to ask questions of people and situations with which ethnographers are unfamiliar. The notion of having 'fresh eyes', or daring to ask stupid questions are often brought up as strategies of fieldwork. Sometimes it is unclear if these strategies are recommended as ways to mitigate the outsider status of the researcher (Gupta and Ferguson 1997), or if they have merit even for situations that are less alien. 
To me, however, the notion of the fieldworker as a clown figure in society due to lack of acumen (Hylland Eriksen 2001) suggests the former. In my case I had a lot of use in being able to ask questions in a manner that suggests some level of insight. At times, this has been feigned having done market research I would have enough knowledge to throw some keywords into a conversation, driving it to areas that were of interest to my project. I cannot of course really know to what extent this 'fake it until you make it' strategy (Silverstein 2006) ever conveyed any expertise to my informants. Something that definitely informs this study has been my previous knowledge about the epistemically sensitive spots of qualitative research work. It allowed me to probe further into client relationships, dealing with respondents and clients in focus groups, and whether selling and doing research projects happen in silos or in unison.

\section{From field notes to articles}

This thesis is the result of a long process. It has gone from a hasty project description about market research as a possible site for understanding measuring devices, to literature reviews both of research into marketing knowledge production (Nilsson 2013) and of how market researchers define their work in industry publications (see Article 1). Further, I have undertaken several months of fieldwork, producing a vast amount of material. How have stacks of books, a 172page research diary and 511 pages of transcripts from 28 interviews come to end up in four short articles and this introduction?

My initial interest in market research primarily revolved around how ideas about consumers are produced. In particular, I was interested in what market researchers themselves thought consumers were: are consumers metaphors or actual people? As the project progressed, however, I became increasingly interested in knowledge production more widely, particularly in relation to the pragmatic goals of market research to inform marketing action. This dualism also seemed central to market researchers themselves as I worked on Article 1. As I had fieldwork access I came to gradually shift my interest to the knowledge production as I saw it at Norna: an activity where sales concerns and client relationships played a large part. Knowing that I wanted to provide an ethnographic account of market research as an activity I tried to set up a plan to cover the breadth of it. From my informants' horizon, this scope appeared to primarily involve the research process and the actors involved. This interest in the work and those involved was something I kept in mind as I set out to plan for articles. 
The writing of articles began as early as in trying to explain to my informants what my research interests were and deciding what to focus on during interviews. The structuring of entries into field notes began production of sorted fieldwork material. As part of making field notes, I noted themes that stimulated my interest in market research as knowledge production, especially when they included tensions or friction around the concept. After transcribing interviews, I then used NVivo to code the research diary and the article transcripts. Early coding cycles focused on sorting out situations, people, the particular projects, as well as looking for recurring topics of conversation, mention of consumers, discussions about methods, respondents and clients, etc. As coding is an iterative process I returned to the material in subsequent coding, adjusting previous categories and adding new ones (Saldana 2012). I kept looking for situations and topics that spoke to my interest in the contradictions involved in producing knowledge in a commercial context, or between the importance of methodological rigour and the need for attracting clients to commission new projects. It was vindicating when I noticed something my informants practised or expressed revealing paradoxical or puzzling implications or consequences. Such cases allowed for taking local epistemic arrangements seriously, giving credit to the reflexivity of my informants as well as allowing me to make a contribution by offering my own account. In this, I arrived at trying to discuss the making of commissioned knowledge as integrated rather than assuming the separateness of conflicting values (i.e. 'commercial concerns' versus 'methodological rigour', etc.). My informants seemed to be able to keep different aspects of their work in mind at the same time without apparent conflict and I thought that I ought to consider my ethnographic account in light of this.

This thesis is unorthodox in that it is an ethnographic compilation thesis. It is intended to inform the social study of knowledge making and the subject of markets and consumers. It primarily draws on and speaks to market studies and STS - especially in its intersection with social and cultural anthropology. In fields like social anthropology and STS where this thesis' ethnographic approach is close to home - the majority of doctoral theses are monographs (notable exceptions include Persson 2011; Lee 2009). Writing a compilation thesis thus puts a burden on this introductory chapter. I outline not only reasons for studying market researchers, and market research as a field of study, but also my field site, and the methodological and theoretical approaches I have taken to study it. While theoretical arguments appear in this introduction, many analytical steps take place in the individual articles. 
The articles included in this thesis were produced according to a plan to capture market research activity in a comprehensive manner. They are also the result of a learning process. The first article provides an account of how to think with local ideas when attempting to engage with performativity. It also begins the process of engaging with how construction of knowledge happens in a setting where researchers have their own ideas about what is going on. After my time at Norna, I wrote three articles with an ethnographic focus, furthering the suggested engagement with local epistemic thought and practice. The ethnographic articles respectively focus on slightly different aspects of market research. Beyond different empirical focus, they each address particular tensions in market research. The second article in this thesis discusses how those studied by market researchers have to be shaped in order to be suitable for research. The third article describes how research processes are knowledge making practices that rely on limiting what the people involved know. Finally, the fourth article addresses how market researchers try to please, but also shape and trap the understanding and attention of the clients of research.

Understanding knowledge production through the relations involved is not only relevant for understanding the work that goes on in market research. The relationships involved in producing knowledge also shape this thesis. When writing articles, I have produced content towards journals with their own research interests, editorial style and review processes. Each article focuses on particular aspects of market research rather than pursuing the overall goal of the thesis. As Article 1 has been published and Articles 2 and 4 have undergone long review processes, the contents of the papers have been transformed to please reviewers and editors, whose motives and dispositions I can only guess at. Just as this project as a whole has changed by what I have learned through the process, the constituent papers are knowledge production shaped by social relations. 



\section{Article Summaries}

Together the articles paint a picture of the knowledge making of market research, starting from epistemology, to features of market research work. The discussion on how knowledge is made begins with the notion of performativity of marketing, which has greatly influenced this thesis. The first article outlines how performativity is relevant, but also why there is need for other approaches, drawing on ethnography and engagement with what local actors think. The second article develops this by comparing ideas about market research as a matter of performing or constructing consumers, and finds the need to acknowledge how actors are taking great care to establish actionable (and in a sense performative) consumer descriptions through managing the objects of study, processes, etc. This care is taken within an epistemic setting, meaning that a comparison with how knowledge making has been studied in STS complements the STSinfluenced work on financial and economic settings. In the third article, I attempt to unpack the narrative of the research process as separable from processes of shaping respondents and receiving actors. Finally, the fourth article continues this exploration of the interconnectedness between knowledge production and concerns over client relationships and sales by looking at how clients are considered as part of research.

\section{Article 1 'Epistemologies in the Wild: Local Knowledge and the Notion of Performativity'}

Our examination reveals a field of practice that does not embrace a simplistic epistemology of market research knowledge as merely representing reality. Market research is thought to produce not just representations of the world, but situations and prerequisites for action. The local epistemology of market research thus acknowledges the reality-changing capacity of market research knowledge.

(Excerpt from Article 1)

The article calls for focusing on local knowledge rather than attempting a purely mechanistic explanation of how marketing knowledge is made. It asks two overall questions: first, how the work to produce and transfer market knowledge is defined and reflected upon in the fields of market research, and what relationships are imagined when articulating an epistemology of market research. Second, it seeks to use the epistemic considerations of market research to inform understanding of how economic theories and models shape markets. A particular focus of inquiry are the implications for using performativity as an analytical concept.

These questions are used to inquire into two handbooks from ESOMAR, drawing on Lynch's notion of epistemography: studying others' ideas about knowledge in a manner that engages with 
rather than rejecting epistemic statements as epistemic matters (Lynch 2013). Thereby, it tries to maintain ties between common understandings of what an epistemology entails in light of the interest in mechanistic explanations when extending the notion of performativity, from financial thought and markets to marketing thought. It argues that the performativity concept as it has been applied to markets does not unpack the making of market knowledge to a satisfying extent. In order to produce an analytically interesting account that has bearing for the situations and people that are purportedly described the question of whether the actors already have an explicit understanding or the dual nature of describing and acting is one that matters.

'Epistemologies in the Wild' shows that in light of a cultural interest in market researchers, what market researchers think characterises market research and speaks to the analytical limits of performativity. It motivates the study of local interpretations, especially given a concern over producing understandings of what local actors are up to that wishes to engage with describing them.

\section{Article 2 'Producing Consumers: Market Researchers' Selection and Conception of Focus Group Participants'}

As market research activity produces consumers as objects of knowledge there is much to learn from the recruitment of those respondents who are to speak on consumers' behalf. By looking at the dismissal of people with certain traits, it becomes apparent that rather than identifying representative consumers among their participants, my informants want to elicit understanding about consumers through researching well-constituted respondents.

(Excerpt from Article 2)

The article deals with the selection routines for recruiting respondents in qualitative focus group interviewing. Market and consumer researchers are loath to include respondents who are seen as having problematic tendencies towards professionalism and avoid including them in research (Belk et al. 2012). I inquire into how and why market researchers at Norna remove problematic participants as part of recruitment. Based on these principles of inclusion and exclusion I discuss how and why some participants are deemed unsuitable for speaking on behalf of consumers, and what consequences this has for the outcome of such research.

The dilemma of who may speak for whom is interesting for constructivist challenges to realism as well as for a performativity approach. The connection between the make-up of the focus group participants and the resulting knowledge about consumers is a reason to address both. Market research has been understood as a site where consumers are either studied directly, or 
alternatively the consumers are constructed and or performed. Local ideas at Norna convey a richer picture, however. The article points to reflexivity as not merely an important practice in ethnographic accounts, but that practising it entails attention to reflexive competence in others. Market researchers' own concerns over how to select research participants is a useful point of departure if one wishes to understand what it is that is studied and what is produced in consumer research. The article succeeds in discussing the carefully selected research participant who may speak for people or concepts. In market research as well as in other forms of social study it is reasonable to exclude traits perfectly common in a researched population in order to obtain material that may be used to give stronger accounts of the qualities of the world, and the shaping of the object of study also affects the object of knowledge.

Conceptually the article draws on marketing scholarship on how consumers are studied, constructed and performed in research. It also uses accounts from STS about how research objects are selected and how to separate relevant signals from irrelevant noise in scientific knowledge production. Both these interests address a wider issue of how studies speak for a world external to the research situation. As the study draws on selection criteria and how they are made sense of, the article also employs a method inspired by the material semiotic approaches of Actor-Network Theory (e.g. Latour 2005). The work to define respondents for study directly manifests in material arrangements to select and exclude research participants: description and conceptualisation is integrated in practice, rather than removed into some other sphere of existence. Ideas and criteria of who to include in a focus group are shown to have direct effects on the consumer descriptions that are produced: reflexive, interpretive consumers arrive as the result of the methods used to understand them.

'Producing Consumers' discusses the respondents and their role in market research according to the market researchers in which I am interested. It ties into a further discussion of what epistemological statements about market research may achieve. Furthermore, it deals with the tensions around representativity and usability in market research and begins suggesting how production of market research results are served by taking into account how 'producing' is both about making and bringing something forth. 


\section{Article 3 'Practices of Not Knowing in Market Research Knowledge Production'}

Making knowledge relies not only on improving on knowledge, but also on limiting information in order to bolster respondent relationships, client reception and trust. Secrecy and ignorance is not only part of the strategic play for client relationships and sales, but plays a part in epistemic practice.

(Excerpt from Article 3)

The article deals with the research process. It explores how market research production is relational, focusing on how researchers manipulate epistemic distance to other actors by means of limiting knowledge and information. The article engages with accounts of how knowledge is made through the collection, selection and refining of facts, which are turned into knowledge that may be used by decision makers to make informed decisions. Instead of accepting Data, Information, Knowledge, Wisdom (DIKW)-oriented approaches to how market knowledge is made through steps from the world (Rowley 2007), it is important to acknowledge how knowledge construction involved movement across a series of operations that are irreducible to a singular process of refining or building knowledge from baser components (Latour 1999).

As an alternative approach to knowledge production the article turns to how limiting knowledge plays a part in making knowledge. It asks in particular how researchers' practices of limiting what others know works in the making of knowledge at Norna. This furthers the thesis' relational focus on market research by asking who are kept from what and when. The article is informed by the study of non-knowledge and secrets as it features in the budding field of agnotology and ignorance studies, as well as in the anthropology of secrets. Empirically, the inquiry deals with Norna's own model for how results are produced, in relation to my observation of how particular projects are undertaken and how Norna co-workers discuss their work.

Market research knowledge is the making of understanding on the part of receiving clients. This is done through limiting insight on the part of both such clients and the respondents. In describing this, the article criticises simplistic linear and realist accounts of how knowledge is made. The notion of knowledge making as the accumulation and refining of facts collected from the world is not a reductive relation between input and outcome. There are however alternative ways of unpacking these assumptions of how results are produced. This article instead discusses how understanding is elicited by paying attention to the importance of limiting information in handling the research relations that market research involves. It explains some of the peculiarities 
of Norna co-workers' interest in reducing transparency and strategic black-boxing in order to enable productive understanding on the part of their clients. My informants are involved with maintaining and adjusting relations on particular epistemic distances to achieve this goal. 'Practices of Not Knowing in market research knowledge production' tells about how market researchers deal with producing knowledge and how it is about bridging, but also keeping and remaking, distances. In relationships of epistemically productive proximities, respondents and clients are recipients of enough information and ignorance to be kept in a certainty interval in relation to Norna researchers. Overcoming gaps in knowledge relies on maintaining certain distances.

\section{Article 4 'Know Your Customer: Client Captivation and the Epistemics of Market Research'}

The Norna case shows a set of local interpretations of and strategies for problems of commissioned knowledge production. Talking about 'help' avoids a rift between the aspects of the work that is about creating information, and the efforts of selling it or otherwise persuading receivers of its value. Market research is most 'helpful' to everyone when the right material meets client preferences.

(Excerpt from Article 4)

The final article turns attention to the client and the market researchers' relations to them. As argued throughout this thesis the clients are of central importance to market researchers' sensemaking. It is clients who often commission market research projects, meaning that researchers have to consider how to both inform and manage their relationship to them in tandem. In particular the article deals with how market researchers think about clients and what is entailed in helping them through market research.

The article analyses how client concerns feature not only in setting up and presenting results, but throughout research projects. Strategies to anticipate as well as affect the dispositions of clients are part of knowledge making. These strategies are approached as objects of capture, drawing on the anthropology of art and its application to material objects such as traps drawing in prey by modelling their behaviour and conceptual surroundings (Gell 1996), the understanding of market-things as part of marketing and how marketing products have to be sold using marketing approaches (Cochoy 2011, 2015). In the case of Norna, I look at the strategies Norna co-workers employed to win over clients to their way of thinking to gain better understanding of how clients are thought to function. This analysis is presented through discussion of how considerations over commissioning clients are pervasive throughout the stages of market research projects. 
'Client captivation and the epistemics of market research' indicates how the unclear use of 'client' is a resource in dealing with the split role of market research as marketing and knowledge making for the market researchers at Norna when they make sense of their work as 'helpful'. By dealing with characterisations of the client, the article notes the ambiguity of usefulness-for-the-client discussion but also recognises how this concept is useful in realising such activity through marketing it. Having status as a trusted advisor, and being on the 'same page' as the client are of course attractive, as such relationships strengthen the position of the researcher. However, it also affects the production and delivery of results, and what it means to claim that findings speak for themselves. 


\section{Discussion of the Articles and Beyond}

The four articles focus on different aspects of what it is to undertake market research work. This discussion will develop a summarising account about what can be learned by studying such knowledge production using a cultural approach. It is a line of inquiry that provides insight into how the Norna and ESOMAR affiliated researchers think they make knowledge in relation to the practices and tools they have to do it. It allows deferring certain tensions to the inquiry, rather than having to establish a priori definitions. Researchers' framing of these tensions is an analytical resource and I explore the implications of studying their sense-making. The discussion section serves as a more comprehensive inquiry into what can be said about market research as a kind of knowledge production based on particular insights into ideas, tools, strategies and practices.

This thesis poses three broad research questions about market research. First, I inquire into how knowledge making practices reflect the local epistemics of market research - including market researchers' explicitly epistemological statements. Second, the thesis is interested in how epistemic work and the epistemological reasoning of market researchers are influenced by the relations maintained with research respondents and receiving clients. Third, I discuss how market research may inform understanding of commissioned knowledge production. Using previous research, further illustration drawing on fieldwork situations and references to other researchers, I will develop a thematic discussion that summarises as well as goes beyond what is already presented in the individual articles.

\section{Knowledge practices and local epistemics}

Question I: How do knowledge making practices in market research reflect the local epistemics of such work?

Paying attention to local epistemologies is a way to ensure that my analysis constitutes a contribution, given that the people that I study already have ample ways of characterising their work. The connection between ways of producing knowledge in practice, and the epistemologies expressed by groups of knowledge producers has formed an initial point of inquiry for this thesis. It is addressed most explicitly in the first article which deals with outright epistemological explanations and argues for taking an epistemographic approach to local epistemologies. This is meant to mitigate the problem of giving accounts of a group of knowledge makers that tells them 'something they already knew and in a language less nuanced than their own' (Pollock and Williams 2015: 22). Simply put, while descriptions of knowledge making may gain from 
perspectives such as the performativity approach briefly outlined in Article 1, the explanatory power of this line of analysis depends on the available accounts among local experts.

The call to undertake research of local epistemic context stresses exploring and engaging with ideas and practice. The articles provide answers to Question I through different engagements with local epistemics - for example, by investigating the principles of selection, their epistemic reasoning and how they are codified into routines which affect results. In Article 2, the principles of participant selection contain ideas about who should participate in studies to speak on behalf on consumers. The use of such prescriptive accounts will shape relationships between researchers and respondents, and ultimately the consumer knowledge produced. Dealing with the role of ignorance in knowledge production, Article 3 furthers understanding of the connection between local reasoning about knowledge production, and the practices involved when undertaking it. By using a contrasting narrative to that which my informants use to explain how they make knowledge, I can show how many of the actions towards limiting what respondents and clients know in market research are useful for unpacking what it means to undertake research in order to inform a receiving party.

In taking on the task of separating the actual signal of the research from the noise present in undertaking studies with respondents, market researchers ensure their own position in the centre of this knowledge production (see Article 3). They also put respondents and clients at productive epistemic distances: within a certainty interval where knowledge may be produced (cf. the notion of the certainty trough in MacKenzie 1990). Further understanding is provided by Article 4 which shows how receiving actors are to be informed by catering to their needs. The practices involved in this are not only shaping the materials produced. There are also strategies to align informative material with receiving clients by affecting clients' reception and dispositions. This implicates readings of market research as making material to shape markets, by showing that it is also intended to shape client relationships and understanding and highlighting how such factors in knowledge making relies on researchers knowing their customers.

\section{On understanding the epistemics of others}

There is an inherent challenge in how to account for other people's ideas in a way that contributes some new understanding. An influential way in which this contribution is performed is through unveiling what truly goes on beneath the surface (cf. Carrier and Miller 1998; Geertz 1972; Zwick and Denegri Knott 2009). Such exposure has value in providing contrast: the researcher describes what others think, and adds an account of how this could be understood 
differently. A complication lies in situations where such descriptions are already adequate: the researcher may become merely a critic offering opposed views, or risk overlooking the ideas of those studied. Alternative approaches include those drawing on ethnomethodology where description focuses on what people involved in a studied situation are thinking and doing (Lynch 1997). In such an approach, the problem of describing what others think is put to the fore and where such an engagement is regarded as the analytical contribution. While my accounts focus on other things from what my informants may regard as central to their work (cf. Latour and Woolgar 1979), I have consistently tried to engage with their view of what is going on. I believe that my informants' ideas merit description if my own analysis is meant to add anything (cf. Strathern 2006). An example of how market researchers speculate about their own work and how it is generated arose during a meeting where the company's qualitative research was discussed:

The meeting went from friendly small talk among the handful of participants to reviewing the firm's organizational plan for qualitative research offerings. An interruption happens when the guidelines state that the qualitative offering is crucially about showing the human perspective, and that it is about describing 'people, not consumers'. One of my key informants looks over to me, and asks 'Hey, Johan that's what you're researching right?' The other meeting participants pause to look at me, and I nod in agreement, mumbling: 'Yes, that is pretty much it right there.' The interrupted meeting then breaks off into a discussion about what it means to describe people and not consumers. A group member argues that it makes sense to strive to study people, as a consumer is the reduction of a person. Another member protests. She sees the consumer as a legitimate way to talk about someone who has been subjected to study, and that talking about people in this context, is more problematic, as only facets of a person are of interest to the market researcher. 'But they are people.' 'Yes, they are people in a context. in the context of consumption.' (Excerpt from field notes)

This 'revelatory incident' (Belk et al. 1989) provides a good example of how my informants are well aware of tensions that are going on. Lynch discusses epistemography as a way to account for the importance of maintaining focus on the fact that there are working definitions of knowledge out there, held by reflexive people (Lynch 2013). I believe that it is important to heed the call for an epistemographic engagement with the cultural knowledge making of others. My informants are aware of what goes on, but have their own interpretations and explanations, from which I gain useful surprises, parallels and contrasts to help my own understanding. In the example above my informants may not have begun this particular discussion had it not been for my presence. However, the interaction between the different researchers sees complex expressions about what sort of things consumers are qua objects of knowledge or study. How one sees what is being said within a context determines what descriptions provide sufficient contrast, surprise or explanation 
to merit a contribution. This is the case whether the prior research is described in an academic article (cf. Locke and Golden-Biddle 1997) or the sense-making that goes on among a group of knowledge makers.

\section{Market research as a relational endeavour}

Question II: How is epistemic work and the epistemological reasoning of market researchers influenced by the relations maintained with research respondents and receiving clients?

The second research question directs attention to the way market research work may be approached by the relationships that characterise this knowledge production. For example, Article 1 notes how client needs matter in the making of marketing knowledge. Market researchers are encouraged to win their client representatives over, making them advocates of the market researchers themselves. Maintaining appropriate relationships between market researcher and respondent thus shapes relationships between these actors to be conductive of the making of consumer knowledge. Article 2 deals primarily with managing relationships vis-à-vis the respondents in qualitative research projects. In this case, the researchers at Norna are loath to deal with the sort of respondents that for some reason challenge a relationship where a certain distance is maintained. They are 'problem respondents', 'professional participants', 'saboteurs', etc. Market research subjects should not become overly familiar with the researchers and are thought to - willingly or unwillingly - distort their answers in interviews, focus groups, etc. Research objects are more informative when carefully managed, even when actual consumers are to be identified.

Market researchers are also shaping the relationships with clients as part of their research. Article 3 discusses the role of maintaining relationships between researchers, respondents and clients, respectively. In these relationships, the managing of who knows what in the research process may position the researchers and the recipients of ignorance/knowledge within the right 'certainty interval' to be able to produce and provide information. Article 4 goes on to focus more specifically on the shaping of relationships between researcher and client. It outlines the strategies through which market researchers devise a position vis-à-vis the client that allows them to be simultaneously won over, sold to and informed through strategic use of research, workshops, etc. This winning over a client to the researchers' way of thinking which is also noted as a goal by the ESOMAR literature of Article 1 is here shown to be constitutive to the relationship through which a client may be dealt with successfully: strengthened, satisfied but interested to know more 
Question II actualises the inherent tensions involved in market research, outlined in the introduction. It is at times unclear what kind of work market research is, in terms of discipline, research tradition, etc. What ends market research strives towards is also somewhat ambiguous. Although the ESOMAR literature, and many marketing scholars discuss market research through the framing of knowledge making, this knowledge appears to be aimed towards other ends than in the social science methods that market research purportedly applies. Further, it appears to be difficult to separate market research knowledge from the concerns over marketing it. The following subsection addresses how to understand this openness analytically by means of thinking about the ambiguity of market research. This is discussed by drawing on local epistemic practices and epistemologies and the tensions over relationships in knowledge making.

\section{The role of ambiguity}

The local epistemology of market researchers, characterisations in the ESOMAR literature as well as the epistemic practices of researchers at Norna display a range of tensions, openness and ambiguity. I propose addressing this openness based on how the first two research questions are discussed by the articles. Understanding market research involves acknowledging how it is a fundamentally ambiguous project, as noted in the introduction. This ambiguity is twofold: First, market research is an activity betwixt and between (cf. Turner 1987) different forms of business, marketing and knowledge making. Second, its output and working concepts (i.e. 'knowledge', 'client', 'help') are at times rather unclear. Given that I try to use an approach to my informants that engages with and tries to work from what they believe, these aspects of ambiguity are consequential.

A recurring issue for my informants is that their output has to work both as research and a sold commodity. Examples of this in the articles include when Anders outlines his model for how customer engagement works - but also uses it in order to engage his own clients - in Article 4. This ambiguity makes the Norna case slightly different from the inquiry into microbiologists and high-energy physicists that Knorr Cetina (1999) studied or the particle physicists of Traweek's ethnography (Traweek 1988). It is not entirely clear what market research makes, at least not without taking into account that it appears to be slightly different things at different times (or more than one thing at a time). Much of the openness of market research can be expressed by the question of whether its product is best understood as a case of knowledge making, or whether to see the product as a commodity. Such a focus shifts inquiry into thinking about tactics for marketing and selling market research products to clients. 
Much of the terminology that my informants and other market researchers espouse is somewhat unclear and sometimes ambiguous. Examples include the notion of 'usefulness' discussed in Articles 1 and 4, the connection between respondents and resulting consumers in Article 2 and the nature of a 'client' in Article 4. It would be an unfortunate conclusion that my informants' vague use of 'client', 'quality', etc. represented a shortcoming on their part. While these terms cause some chagrin for whoever tries to explain them (as I try to do in this thesis) they do see use, and may be understood as useful. This is not something that is unique to this particular case. Many other studies have noted how relative openness of terminology may be approached as productive rather than debilitating (e.g. Brown et al. 2013; Rappert 2001; Woolgar and Cooper 1999). While knowledge making often relies on clarity of definitions (Suddaby 2010) alternatives may be found in the study of marketing concepts. For example Steven Brown, Pierre McDonagh and Clifford J. Schulz (Brown et al. 2013) discuss what constitutes successful branding by employing the concept of myths.

Examining the 'Titanic' brand, Brown et al. argue that concepts may resonate especially well with people because they are profoundly ambiguous. They suggest that branded content often carries multiple meanings: for instance, words such as 'coke' and 'it' may in themselves mean several different things but 'Coke Is It' has particularly evocative power because it is even more openended (Brown et al. 2013). Indeed, the power to be different things for different people may be considered a strength from the perspective of knowledge production (cf. Flyvbjerg 2006). Similarly, market research appears at times to be kept vague for the very sake of making sure that findings may resonate with clients whose dispositions and understandings vary (Brown et al. 2013). The openness of interpretation of a phenomenon such as a myth or a brand means that it can resonate more profoundly with more people.

Market research is partly ambiguous in that it operates betwixt and between different types of activity. Such a position is not only awkward but quite productive. An example of this from anthropology may be found in Victor Turner's treatment of liminality - states of being between or beyond categories - and anti-structure in relation to social structure (Turner 1987; Turner et al. 2011). My researchers are involved in a somewhat marginal activity that seeks to know markets in order to change them, by methods that are neither marketing manoeuvring nor science. They produce results that are valuable only so far as they can be used to affect the situation which they describe. 
It is valuable to defer the issue of whether market research is 'actually' about sales and marketing or if it is about doing knowledge work. Instead the articles have shown how market researchers see, use and sometimes worry about this tension. For instance, my informants are expressing worries that revolve around tension between good enough research versus having a sellable product (see Article 4). This tension is handled by asserting that good research is supposedly also good for informants who ought to recognise such merit. This conveys a fuller cultural picture than would have been gained through an a priori assumption about the nature of this activity. The same goes for other tensions within the market research field, such as that between market research being an art requiring creativity, as well as a range of methods applying social science calling for rigour. It also speaks to the epistemological ambiguity that market research handbooks express over the outcomes of research: whether it is inspired insight, or factual information (see Article 1).

The issue of ambiguity leading over to the open-endedness of market research production actualises the relationship and marketing oriented work that appears to be ingrained in the research. It appears that the marker researchers that I study gain a lot rather than suffer from the ambiguities in their work. Producing knowledgeable clients through study of respondents relies on non-knowledge (Article 3), consumer representations are made through establishing controlled non-representational respondents (Article 2) and helping clients depends on capturing them (Article 4). Tensions are not mere problems but are also interacted with and used as resources.

One of the aspects where this thesis set out do something different from what critical approaches to market research have done in the past was in how to contribute understanding to a situation which is already understood locally. Undertaking such ethnographic observation still appears to have led to my offering an account of market research which varies from the general characterisation (cf. Belk et al. 2012; Hamersveld and de Bont 2008; Kotler et al. 2016) However, I am not content merely to claim that this means that what market researchers do and say they do are different things. Nor am I happy with merely accounting for how market researchers make sense of their world: I have set out to engage with this sense-making. Rather, one may make sense of the many things market researchers say they do and what they do, in ways that join what would otherwise remain unconnected. Doing so has meant following market researchers' concerns over relations in their knowledge making and to pondering whether the connection between marketing and producing marketing knowledge can be considered in tandem. 
Understanding this connection between commercial and epistemic concerns brings to the fore the issue of what characterises commissioned knowledge production.

\section{Understanding commissioned knowledge production in market research}

Question III: How do ideas and practices in market research inform understanding of commissioned knowledge production?

Focusing on epistemics and paying attention to the ambiguities of market research are useful tools when examining market research as a case of commissioned knowledge production. Tensions over such research and its ends cannot be readily separated from the relationships with involved clients and respondents. In these cases, neither descriptions of the knowledge making nor the market making aspects of production in market research cancel out the other. These phenomena appear simultaneously relevant to market research. The articles in this thesis provide materials for starting to address the third question. Article 1 makes the point that market research is framed as a particular form of knowledge making in the ESOMAR literature. It is presented as an 'art' rather than 'science', even as the ESOMAR handbook characterises such research as applying methods from the social sciences. Further, the output of marketing research is thought to have merit according to its actionability, referring to the role of market research as supporting business decisions. As noted in Article 4, whether market research fulfils this purpose is typically beyond the ken of researchers at firms such as Norna. The relational concerns implied by this imperative to support clients' decisions are ubiquitous, however.

Throughout this study of market research, there are many examples of how researchers consider their work not only as the production of knowledge but also as effort in affecting clients and selling research. Articles 2 and 3 show concerns on the part of marketers that are more complex than what would be conveyed by discussing the work to make knowledge about consumers as a strictly realist or constructivist endeavour. As shown by emphasising acts of limiting what is known in Article 3, relationships are not considered separate from the making of knowledge or ignorance. Further, Article 4 argues that the work to get clients on the same side as researchers at Norna mixes up information with the shaping of clients' conceptual frames, getting them to a particular state through rhetoric, presentation and informing. In this, Article 4 notes that outcomes of market research are objects of marketing, even when they pertain to marketing action. 
Beyond taking an epistemographic approach and acknowledging the ambiguity in this relational endeavour, there is a need to explore other perspectives on the making of knowledge for commissioning clients. In order to do this, I will draw on studies of other makers of 'commissioned knowledge'. Such examples include industry analysis studied by Pollock and Williams (2015) as well as financial analysis studied by Knorr Cetina (2010). Both these studied domains share features with market research, such as producing results meant to inform clients who want to use them. As shown in the articles of this thesis, research into local epistemic practices point the way to understanding knowledge making and the relationships with both clients and the respondents involved, in a new light.

Just like market researchers, industry analysts are well aware of the tensions involved in their work to inform clients. The Gartner analysts that Pollock and Williams study acknowledge that they sometimes 'describe' and sometimes 'direct' markets by their recommendations (Pollock and Williams 2015). Market researchers appear more torn of over this ambiguity. My informants ascribe directive agency with their clients, and at most claim licence for making interpretive decisions. These differences may be the result of the infrastructures and relationships that characterise their respective industries. Market researchers such as those at Norna are to a large extent providing their clients with custom research and in contrast to firms like Gartner, only a minority of their research projects are syndicated. Contacts with clients are specific, if not always personal. This has parallels in the specialisation exemplified by Knorr Cetina (2010). She describes how financial analysts seek to understand the situation for a fairly limited range of clients in order to provide them with recommendations, much like niche industry analysts that operate in a more specialised capacity than Gartner (Knorr Cetina 2010; Pollock and Williams 2015). In the case of Gartner on the other hand, analysts describe the IT market as being for an open-ended audience of companies in need of information about what to purchase. Gartner liken themselves to journalists and stress the importance of independence. They primarily offer syndicated reports that in turn are used to provoke interest for personal advice from the analysts (Pollock and Williams 2015). All this is suggestive of how the specifics of the client relationships may have consequences for how commissioned knowledge production is undertaken.

Commissioned knowledge production is also shaped by relationships with those that are researched as part of such practice. Gartner analysts readily acknowledge that much like 'ethnographers' they play part in changing the situation they purport to describe through their intimate contact with the suppliers of technical systems (Pollock and Williams 2015). This is 
rather different from the case of market research in the sense that market researchers at Norna and elsewhere produce knowledge meant to represent a more general public. As noted by both Lezaun and Soneryd (2007) and explored in respondent selection (see Article 2), a general public is one that is not overly personal, nor informed. Contacts are often one-off or brief, and professional relationships between researcher and respondents are only allowed to be one way: professional respondents are often thought of as problem respondents (Belk et al. 2012). Additionally, while market researchers and industry analysts consider their job to feature the need to get behind facades to explore truth, this need is conceptualised differently. The industry analysts are researching industry actors, whose business interest is affected by the ranking they receive by analysts such as Gartner (Pollock and Williams 2015). Respondents in market research may be professional, undermining their usefulness in consumer research. Commissioned knowledge production inherently concerns both epistemic and relational concerns in dealing with those objects of subjects that are studied.

As shown by contrasting the results from this study with previous work on other forms of commissioned knowledge production, the particularities of relations between involved actors provide a fruitful way to account for the differences between these alternative domains of commissioned knowledge production. In this, acknowledging the role of relationships in the making of commissioned knowledge production resembles Pollock and Williams' (2015) call to 'maintain a focus on knowledge production whilst also offering insights into how knowledge outputs result from the particular demands of their production, which include verification by an audience' (Pollock and Williams 2015: 324).

The relationships involved in making commissioned knowledge are constitutive to the results together with the methods and materials used. As shown by paying attention to how market researchers see their work and the relationships this activity involves, connections vis-à-vis clients and respondents are not only a shaping factor but are subject to strategising and manipulation. Market researchers try to anticipate, please as well as shape client dispositions (see Article 4), they select respondents useful for producing useful materials (Article 2) and they mitigate and affect epistemic distances to produce relationships with productive certainty intervals (Article 3). Market research is a relational knowledge making endeavour and it matters that knowledge is made on a commissioned basis. 
Many concerns are at play in commissioned knowledge production. Examples discussed in this thesis involve usefulness, actionability, product- and saleability, methodological and relational concerns as well as informing understanding. Marilyn Strathern (2006) suggests that there are different models of dealing with knowledge, where managerial concerns revolve around limiting uncertainty and research concerns rely on a certain level of surprise. As my study shows, these concerns are intimately intermingled during the commissioned production of consumer and marketing knowledge. Regardless of whether one begins to understand commissioned knowledge production from the perspective of making a sellable product or the making of knowledge, market researchers are involved in managing relationships. These relationships include clients and respondents, and they shape the outcome of their research (be it knowledge, a product, or a knowledge-product). Results of market research are not only the outcome of the methods and underlying ideas about markets and how to know them held by market researchers themselves. The work performed in context - including the relationships involved - provides important insight to commissioned knowledge production. 



\section{Concluding Remarks and Further Research}

Imagine returning to those aisles in the supermarket where this thesis started off. This inquiry into market research has described the setting where many ideas of what you want are made. The supermarket environment has been shaped by those ideas about you, produced by researchers, for the benefit of clients who want to sell to you. As this thesis has shown, ideas about you as a consumer, voter, viewer, etc. are not only interesting as material directing marketing efforts. It appears that descriptions of us qua consumers are shaped by assumptions and conventions of how to undertake research. People speak on your behalf and clients use this knowledge to get to you. Further, the making of knowledge in marketing and consumer research is a deeply involved process, joining several actors: It matters that market research is produced through managing sometimes unreliable respondents, and executed under pressure to deliver results to commissioning clients. Market researchers deal with respondents to get to consumers, and with clients both in order to make ends meet and fill the purpose of market research: to help market actors in their decisions about how to attract you as you walk the supermarket aisles or move elsewhere in society.

This thesis has worked to do three things. The initial and more concrete objectives were about exploring the epistemics of market research. Particularly, I have been interested in the connection between research and research output and what the study of market researchers says about how markets are rendered knowable and open for action. Further, the thesis uses market research as a sounding board for a discussion about what may be said about the handling of ambiguities in commissioned knowledge making. The discussion of how market research is undertaken has been considered in connection with the relations that feature in such commissioned knowledge production. This issue is of particular interest given how knowledge and action tend to be closely associated in market research.

The study dealt with how market researchers make knowledge about markets and consumers. It will likely differ from accounts of how marketing professionals have us figured out better than we have ourselves, a common alarmist trope with a long history (Packard 1991). Instead, market researchers in this study have been shown to employ routines both for finding out and for persuading their clients, who in turn are often marketers themselves. They sort and account for people in specific ways in order to produce knowledge to appeal to their ideas of clients' dispositions. If people are made in market research, as I suggested in the introduction (Hacking 1999), they are importantly made by people, for people. At stake for my informants is making 
material that is of high quality, as the result of diligent effort, which works for the receiving client. This gives rise to further questions not just for us but for market researchers themselves. If the receiving client must be targeted and shaped by material, then making knowledge for clients relies on knowing clients. Here, one knowledge problem begets another.

Making the market researchers into my object of study and maintaining interest in how their ideas, practices, tools and surroundings interact, has shown how the marketing knowledge of the world is not merely something that brings propensity for action. It is the result of purposeful production processes and decisions made on the part of reflective researchers. Viewing market research as cultural has allowed me to leverage the local epistemic ideas and practices as well as the relations that researchers are involved in to explain the particulars of this kind of knowledge production. My informants are aware of the ambiguities that characterise their work and they are not lacking in approaches for trying to handle these tensions. This can be drawn on in order to think about making knowledge meant to convince and be put into practice. Such knowledge, oriented around usefulness, actionability or similar pragmatic concerns, are not merely relevant in the case of the ambivalent product of market research (where knowledge is a commodity to be sold). The market research case may also be compared with the domains where financial and industry analysis is made and sold (Knorr Cetina 2010; Pollock and Williams 2015), and perhaps further by extending the scope to the making of public information, policy advice or intelligence work. In all these fields, knowledge is not just produced to correspond with the world but has to prepare actors in relating to it. The results from this study as regards market researchers show that they have strategies for how this may be brought about.

Market research features many explicitly epistemological ideas but also formulations about client reception and sales. The specific ways in which market research is undertaken has effects on the outcomes in the form of results and reports. Market researchers have ideas about what clients want, can handle, and need to succeed. These ideas about the client inform their work, from the way projects are solicited and set up, to how they are undertaken, analysed and reported. Market researchers select respondents and manage the information that they produce according to their ideas about what is a useful signal from consumers and markets, and what they consider noise that is not of use to clients. Further, they maintain helping relationships with their clients where they attempt to give advice in the form of evocative and useful results. The map makers' dilemma appears to be present but the importance of maintaining distances and relations means that this dilemma is not an epistemological quandary that happens in a vacuum. 
Research answers questions as well as suggesting new lines of inquiry. Just as making knowledge about markets and consumers requires researchers to determine and manage the actors involved in research projects, this thesis has asked questions, provided answers and in turn given rise to new questions. While I stress the need for studying the relationships at play in knowledge making, my focus has remained on the market researchers themselves. Further study into the interaction between researchers and clients will yield new insights into the role of contributing and receiving actors in commissioned knowledge production. If staying with the researchers, looking into situations where producers of knowledge deal with determining who their users are may also be a fruitful line of inquiry. Subsequent study could also look more specifically into how the researched see their role and how their understanding of research situations shape results.

More focused inquiry into the research projects would also be able to yield more detail about how market researchers regard what they know in the research project: how are ideas about what transpired in recruitment and vetting shaping researchers' analysis of results? What is conveyed to clients? Clients and their reception have been considered as a factor in researchers' understanding of market research. I have found that ideas about clients matter in the making of material aimed at them. The extent to which clients are aware of the details of market research production, and whether it affects their understanding of results would give an alternative understanding of the role of relationships and ignorance in forming understanding about consumers. Further clarity of how knowledge and non-knowledge are made in tandem to foster actionable understanding and managing epistemic distance would be gleaned from the study of other reception sensitive cases, such as the making of materials for policy, public information campaigns or marketing communication. Similarly, research into how captation is achieved through the appreciation as well as shaping of dispositions and preferences of those receiving knowledge could be extended to other situations where a material is made in relation to a commissioning recipient. 



\section{Appendix}

As a methodological addendum, I here include a late version of the interview guide that I used for the general interviews conducted with co-workers at Norna. As all interviews were conducted in Swedish the original guide has been translated into English. The guide is more elaborate than was the case during the interviews. Rather than focusing on the guide to the letter I used it to keep track of my more general set of interests (represented by points $\mathrm{I}-\mathrm{V}$ in the guide). Most of the time, I kept in mind the five sections and their formulations of research interests, posed the questions in the order I saw fit, and used some of the sub-questions and prompts as needed. This shows the tendency towards the open-ended pole on the spectrum of the semi-structured interview as a format.

\section{Interview guide}

The purpose of the study is to gain perspective on the interview subject's role, and background as a market researcher. Interview subjects' view of the conditions for doing market research, the role as market researcher and ideas about market research as knowledge production is also covered.

\section{Background}

Section to establish contact with the interview subject as well as gather general information.

- Could you tell me about how you came to work with research?

- For how long have you worked with research?

- How would you describe your role?

- What sort of educational background do you have?

\section{Ideas of what it is to be a market researcher}

Section focuses on the market research profession.

- Would you say you are doing market research here?

- Market research?

○ Consumer research?

- How would you describe what you do?

- What do you think about the term market research?

- What do you think characterises a good (market) researcher?

- Has your idea of market research changed?

- Compared to before you worked here?

○ Do you think market research is developing in any particular direction?

- How do you stay informed about how other researchers work? 


\section{Ideas about market research as knowledge}

Section's purpose is to understand market research as an activity.

- What do you think characterises good research?

$\circ$ Does thinking in terms of quality help?

- What does a good study have to achieve?

- Convince?

- Truth?

- Sales?

- Be useful?

- What do you see as recurring problems in research?

- Have you any examples of market research missing its goal?

- Have you seen changes in how work is done over your career?

- Do you see any differences between academic and market research?

- How do you think you use the term 'consumer' in your work?

O Is it the consumer that you pose questions to? Is it an aggregate? Is it an aspect of a respondent that gets actualised by the study?

- Are there consumers out there in the wild?

- Are people and consumers the same thing?

\section{Ideas about the role of market research in society}

Section works towards understanding how market research as a phenomenon relates to other things.

- Do you meet people who are critical of market research?

- What are they critical of?

o What do you think about that?

- Do you find that people generally understand market researchers?

- Why do clients purchase market research?

- How do you work with helping your clients?

- Could a research project be good but not appreciated by a client?

- Do clients understand your work?

- What do you think about the role market research has in society today?

$\circ$ Are they useful?

- To whom? 


\section{Closing}

Section closes the interview and makes sure the interview subject has a chance to ask questions and add thoughts.

- Have you had any thoughts while we have spoken?

- Do you have any questions for me?

- What did I miss?

- May I come back to you if I have any questions?

- Please get back to me if you have any questions or have anything to add. 



\section{References}

Anderson, Chris. 2008. 'The End of Theory: The Data Deluge Makes the Scientific Method Obsolete.' Wired.com, 20080623. Available at http://archive.wired.com/science/discoveries/magazine/16-07/pb theory, accessed 19 Feb 2015.

Andrejevic, Mark. 2005. 'Nothing comes between me and my CPU: Smart clothes and “ubiquitous" computing.' Theory, Culture \& Society 22 (3): 101-119.

Applbaum, Kalman. 1998. 'The sweetness of salvation: consumer marketing and the liberalbourgeois theory of needs 1.' Current Anthropology 39 (3): 323-350.

Araujo, Luis. 2007. 'Markets, market-making and marketing.' Marketing Theory 7 (3): 211-226.

Araujo, Luis, John Finch, and Hans Kjellberg. 2010. Reconnecting Marketing to Markets: OUP Oxford.

Ariztia, Tomas. 2015. 'Unpacking insight: How consumers are qualified by advertising agencies.' Journal of Consumer Culture 15 (2):143-162.

Arvidsson, Adam. 2001. 'From counterculture to consumer culture: Vespa and the Italian youth market, 1958-78.' Journal of Consumer Culture 1 (1): 47-71.

Arvidsson, Adam. 2005. 'Brands: A critical perspective.' Journal of Consumer Culture 5 (2): 235-258.

Baltscheffsky, Susanna. 2012. 'Klimatoro bland unga utbredd.' Svenska Dagbladet. Available at https://www.svd.se/klimatoro-bland-unga-utbredd, accessed 18 Sep 2017.

Bauman, Zygmunt. 2013. Consuming Life: John Wiley and Sons.

Belk, Russell, Melanie Wallendorf, and John Sherry. 1989. 'The sacred and the profane in consumer behavior: Theodicy on the odyssey.' Journal of Consumer Research 16 (1):138.

Belk, Russell, Eileen Fischer, and Robert V. Kozinets. 2012. Qualitative Consumer and Marketing Research: SAGE Publications. 
Bell, Genevieve, Tom Boellstorff, Bill Maurer, Melissa Gregg, and Nick Seaver. 2015. Data: Now Bigger and Better! Chicago, IL: Prickly Paradigm Press.

Berghoff, Hartmut, Philip Scranton, and Uwe Spiekermann. 2012. The Rise of Marketing and Market Research. New York: Palgrave Macmillan.

Boffey, Daniel. 2017. 'Food brands “cheat” eastern European shoppers with inferior products.' The Guardian, 20170915. Available at https://www.theguardian.com/inequality/2017/sep/15/food-brands-accused-ofselling-inferior-versions-in-eastern-europe, accessed 18 Sep 2017.

Bogart, Leo. 1957. 'Opinion research and marketing.' The Public Opinion Quarterly 21 (1): 129-140.

Bogart, Leo. 1963. 'Inside marketing research.' The Public Opinion Quarterly 27 (4): 562-577.

Bowker, Geoffrey C., and Susan Leigh Star. 2000. Sorting Things Out: Classification and Its Consequences. Cambridge, MA and London: MIT Press.

Breddam, Mads Dupont. 2015. 'Loyalitet i praksis: En etnologisk kulturanalyse af fænomenet den loyale forbruger.' $\mathrm{PhD}$ Thesis. Københavns Universitet, Det Humanistiske FakultetFaculty of Humanities, Saxo-Instituttet-Arkæologi, Etnologi, Historie og Græsk og Latin [SAXO Institute of Archaeology, Ethnology, Greek \& Latin History].

Brown, Stephen, Pierre McDonagh, and Clifford J Shultz. 2013. 'Titanic: Consuming the myths and meanings of an ambiguous brand.' Journal of Consumer Research 40 (4): 595-614.

Callon, Michel, ed. 1998. The Laws of the Markets. Hoboken, NJ: Wiley.

Callon, Michel. 2005. 'Why virtualism paves the way to political impotence. Callon replies to Miller.' Economic Sociology: European Electronic Newsletter 6:2, February 2005.

Camic, Charles, Neil Gross, and Michèle Lamont. 2012. Social Knowledge in the Making. Chicago, IL: University of Chicago Press.

Canniford, Robin, and Avi Shankar. 2012. 'Purifying practices: How consumers assemble romantic experiences of nature.' Journal of Consumer Research 39 (5): 1051-1069. 
Carrier, James.G., and Daniel Miller. 1998. Virtualism: A New Political Economy. Oxford: Berg Publishers.

Cheney-Lippold, John. 2011. 'A new algorithmic identity: Soft biopolitics and the modulation of control.' Theory, Culture \& Society 28 (6): 164-181.

Clifford, James, and George E. Marcus. 1986. Writing Culture: The Poetics and Politics of Ethnography, School of American Research Advanced Seminar, Berkeley, CA: University of California Press.

Cochoy, Franck. 1998. 'Another discipline for the market economy: Marketing as a performative knowledge and know-how for capitalism.' In The Laws of the Markets, edited by Michel Callon, pp. 194-221.Hoboken, NJ: Wiley.

Cochoy, Franck. 2004. 'Is the modern consumer a Buridan's donkey? Product packaging and consumer choice.' In Elusive Consumption, edited by K. Ekström and H. Brembeck, pp. 205-227. Oxford: Berg Publisher.

Cochoy, Franck. 2005. 'A brief history of "customers," or the gradual standardization of markets and organizations.' Sociologie du travail 47: e36-e56.

Cochoy, Franck. 2009. 'Driving a shopping cart from STS to business, and the other way round: On the introduction of shopping carts in American grocery stores (1936-1959).' Organization 16 (1): 31-55.

Cochoy, Franck. 2011. “"Market-things inside”: Insights from Progressive Grocer (United States, 1929-1959).' In Inside Marketing: Practices, Ideologies, Devices, edited by D. Zwick and J. Cayla. Oxford: Oxford University Press.

Cochoy, Franck. 2015. 'Consumers at work, or curiosity at play? Revisiting the prosumption/value cocreation debate with smartphones and two-dimensional bar codes.' Marketing Theory.

Cochoy, Franck, Johan Hagberg, and Roland Canu. 2015. 'The forgotten role of pedestrian transportation in urban life: Insights from a visual comparative archaeology (Gothenburg and Toulouse, 1875-2011).' Urban Studies 52 (12): 2267-2286.

Daston, Lorraine. 1995. 'The moral economy of science.' Osiris 10: 2-24. 
Davies, Charlotte Aull. 2012. Reflexive Ethnography: A Guide to Researching Selves and Others. London: Routledge.

Dear, Peter. 2001. 'Science studies as epistemography.' In The One Culture? A Conversation about Science, edited by J. A. Labinger and Harry M. Collins, pp. 128-141. Chicago, IL: University of Chicago Press.

Desroches, Pascale, and Marcoux, Jean-Sébastien. 2011. 'The making of the sensuous consumer.' In Inside Marketing: Practices, Ideologies, Devices, edited by D. Zwick and J. Cayla, pp. 162-182. Oxford: Oxford University Press.

Díaz Ruiz, and Carlos Adrian. 2014. Market representations in action: Foundations for the performativity of representations in marketing. Helsinki: Department of Marketing, Hanken School of Economics.

ESOMAR. 2007. 'ICC/ESOMAR international code on market and social research.' Amsterdam: ICC/ESOMAR. Available at https://www.esomar.org/uploads/public/knowledge-and-standards/codes-andguidelines/ESOMAR ICC-ESOMAR Code English.pdf, accessed 29 January 2018.

Flyvbjerg, Bent. 2006. 'Five misunderstandings about case-study research.' Qualitative Inquiry 12 (2): 219-245.

Geertz, Clifford. 1972. 'Deep play: Notes on the Balinese cockfight.' Daedalus 101 (1): 1-37.

Geertz, Clifford. 1973. The Interpretation of Cultures: Selected Essays. New York: Basic Books.

Geiger, Susi, Debbie Harrison, Hans Kjellberg, and Alexandre Mallard. 2014. Concerned Markets: Economic Ordering for Multiple Values. Cheltenham: Edward Elgar Publishing.

Gell, Alfred. 1996. 'Vogel's net traps as artworks and artworks as traps.' Journal of Material Culture 1 (1): 15-38.

Grandclément, Catherine, and Gérald Gaglio. 2011. 'Convoking the consumer in person: The focus group effect.' In Inside Marketing: Practices, Ideologies, Devices, edited by D. Zwick and J. Cayla. Oxford: Oxford University Press. 
Gupta, Akhil, and James Ferguson. 1997. 'Discipline and practice: "The field" as site, method, and location in anthropology.' Anthropological Locations: Boundaries and Grounds of a Field Science 100: 1-47.

Hacking, Ian. 1999. 'Making up people.' The Science Studies Reader 18: 590.

Hamersveld, Mario van, and Ceres de Bont. 2008. Market Research Handbook (5th edn). Hoboken, NJ: Wiley.

Hannerz, Ulf. 2006. 'Studying down, up, sideways, through, backwards, forwards, away and at home: Reflections on the field worries of an expansive discipline.' Locating the Field: Space, Place and Context in Anthropology 42: 23.

Harrison, Debbie, and Hans Kjellberg. 2010. 'Segmenting a market in the making: Industrial market segmentation as construction.' Industrial Marketing Management 39 (5): 784 792.

Hedlund, Monica. 2011. 'Rykten på nätet oroar företagare.' Dagens Nyheter, 20110418. Available at http://www.dn.se/ekonomi/rykten-pa-natet-oroar-foretagare/, accessed 18 Sep 2017.

Heiskanen, Eva. 2005. 'The performative nature of consumer research: Consumers' environmental awareness as an example.' Journal of Consumer Policy 28 (2): 179-201.

Hylland Eriksen, Thomas. 2001. Small Places, Large Issues: An Introduction to Social and Cultural Anthropology. London: Pluto Press.

Kjellberg, Hans, and Claes-Fredrik Helgesson. 2006. 'Multiple versions of markets: Multiplicity and performativity in market practice.' Industrial Marketing Management 35 (7): 839_ 855.

Kjellberg, Hans, and Claes-Fredrik Helgesson. 2010. 'Political marketing: Multiple values, performativities and modes of engaging.' Journal of Cultural Economy 3 (2): 279-297.

Knorr Cetina, Karin. 1999. Epistemic Cultures: How the Sciences Make Knowledge. Cambridge, MA: Harvard University Press. 
Knorr Cetina, Karin. 2010. 'The epistemics of information: A consumption model.' Journal of Consumer Culture 10 (2): 171-201.

Kotler, Philip, Kevin Lane, Meirad Brady, Malcolm Goodman, and Torben Hansen. 2016. Marketing Management (3rd European edn). New York: Pearson (Textbook).

Latour, Bruno. 1987. Science in Action: How to Follow Scientists and Engineers through Society. Cambridge, MA: Harvard University Press.

Latour, Bruno. 1999. Pandora's Hope: Essays on the Reality of Science Studies. Cambridge, MA: Harvard University Press.

Latour, Bruno. 2005. Reassembling the Social: An Introduction to Actor-Network-Theory. Oxford: Oxford University Press.

Latour, Bruno, and Steve Woolgar. 1979 [2013]. Laboratory Life: The Construction of Scientific Facts, ed. J. Salk. Princeton, NJ: Princeton University Press.

Law, John. 2004. After Method: Mess in Social Science Research. London: Routledge.

Lee, Francis. 2009. Letters and Bytes: Sociotechnical Studies of Distance Education. PhD Thesis Linköping: Department of Thematic Studies, Linköping University.

Lévi-Strauss, Claude. 1966. The Savage Mind. Chicago, IL: University of Chicago Press.

Lezaun, Javier. 2007. 'A market of opinions: The political epistemology of focus groups.' The Sociological Review 55: 130-151.

Lezaun, Javier, and Linda Soneryd. 2007. 'Consulting citizens: Technologies of elicitation and the mobility of publics.' Public Understanding of Science 16 (3): 279-297.

Lien, Marianne E. 1997. Marketing and Modernity: An Ethnograpby of Marketing Practice. New York: Berg Publishers.

Lien, Marianne E. 2004. 'The virtual consumer: constructions of uncertainty in marketing discourse.' In Market Matters: Exploring Cultural Processes in the Global Marketplace, edited by Christina Garsten and Monica Lindh de Montoya, pp. 46-66. Houndsmills, NY: Palgrave Macmillan. 
Lindquist, Johan A. 2009. The Anxieties of Mobility: Migration and Tourism in the Indonesian Borderlands. Hawai'i: University of Hawai'i Press.

Locke, Karen, and Karen Golden-Biddle. 1997. 'Constructing opportunities for contribution: Structuring intertextual coherence and "problematizing" in organizational studies.' Academy of Management Journal 40 (5): 1023-1062.

Lynch, Michael. 1997. Scientific Practice and Ordinary Action: Ethnomethodology and Social Studies of Science. Cambridge: Cambridge University Press.

Lynch, Michael. 2000. 'Against reflexivity as an academic virtue and source of privileged knowledge.' Theory, Culture \& Society 17 (3): 26-54.

Lynch, Michael. 2013. 'Ontography: Investigating the production of things, deflating ontology.' Social Studies of Science 43 (3): 444-462.

MacKenzie, Donald. 1990. Inventing Accuracy. Cambridge, MA: MIT Press.

MacKenzie, Donald. 2007. 'Is economics performative? Option Theory and the construction of derivative markets.' In Do Economists Make Markets?: On the Performativity of Economics, edited by D. A. MacKenzie, F. Muniesa, and L. Siu, pp. 54-86. Princeton, NJ: Princeton University Press.

MacKenzie, Donald, and Yuval Millo. 2006. An Engine, Not a Camera: Not a Camera: How Financial Models Shape Markets. Cambridge, MA: MIT Press.

MacKenzie, Donald, Fabian Muniesa, and Lucia Siu. 2007. Do Economists Make Markets?: On the Performativity of Economics: Princeton, NJ: Princeton University Press.

Malinowski, Bronislaw. 1961 [1922]. Argonauts of the Western Pacific: An Account of Native Enterprise and Adventure in the Archipelagoes of Melanesian New Guinea. Long Grove, IL: Waveland Press.

Marcus, George E. 2006. 'Where have all the tales of fieldwork gone?’ Ethnos 71 (1): 113-122.

Mason, Katy, Hans Kjellberg, and Johan Hagberg. 2015. 'Exploring the performativity of marketing: theories, practices and devices.' Journal of Marketing Management 31 (1-2): 1-15. 
Miller, Peter, and Nikolas Rose. 1997. 'Mobilising the consumer: Assembling the subject of consumption.' Theory, Culture and Society 14 (1): 1-36.

Moeran, Brian. 2004. 'Marketing Ethnography: Disciplines and Practices.' In Market Matters: Exploring Cultural Processes in the Global Marketplace, edited by Christina Garsten and Monica Lindh de Montoya, pp. 23-45. Houndsmills, NY: Palgrave Macmillan.

Moisander, Johanna, and Anu Valtonen. 2006. Qualitative Marketing Research: A Cultural Approach. London and Thousand Oaks, CA: SAGE Publications.

Moisander, Johanna, Anu Valtonen, and Heidi Hirsto. 2009. 'Personal interviews in cultural consumer research - post-structuralist challenges.' Consumption, Markets and Culture 12 (4): 329-348.

Monaghan, John, and Peter Just. 2000. Social and Cultural Anthropology: A Very Short Introduction. Oxford: Oxford University Press.

Mouncey, Peter, and Frank Wimmer. 2007. Market Research Best Practice: 30 Visions for the Future. Hoboken, NJ: Wiley.

Muniesa, Fabian, and Anne-Sophie Trébuchet-Breitwiller. 2010. 'Becoming a measuring instrument: An ethnography of perfume consumer testing.' Journal of Cultural Economy 3 (3): 321-337.

Nilsson, Johan. 2013. Studying Consumers? Recent Social Science Interest in Market Research, working paper. Technology and Social Change Department of Thematic Studies. Linköping: Linköping University Press.

Ogilvy, David, and Alan Parker. 2011. Confessions of an Advertising Man. London: Southbank Publishing.

Osborne, Thomas, and Nikolas Rose. 1999. 'Do the social sciences create phenomena?: The example of public opinion research.' British Journal of Sociology 50 (3): 367-396.

Packard, Vance. 1991 [1957]. The Hidden Persuaders. Harmondsworth: Penguin Books.

Paterson, Mark. 2006. Consumption and Everyday Life. London: Routledge Chapman \& Hall. 
Persson, Alma. 2011. Changing Boundaries, Defending Boundaries: Gender Relations in the Swedish Armed Forces: PhD Thesis. Linköping: Department of Thematic Studies, Linköping University.

Pollock, Neil, and Robin Williams. 2015. How Industry Analysts Shape the Digital Future. Oxford: Oxford University Press.

Rappert, Brian. 2001. 'The distribution and resolution of the ambiguities of technology, or why Bobby can't spray.' Social Studies of Science 31 (4): 557-591.

Rowley, Jennifer E. 2007. 'The wisdom hierarchy: Representations of the DIKW hierarchy.' Journal of Information Science 33 (2): 163-180.

Ruppert, Evelyn. 2012. 'c. Seeing population: Census and surveillance by numbers.' In Routledge Handbook of Surveillance Studies, edited by Kirstie Ball and Kevin Haggerty, pp. 209216. London: Routledge.

Saldana, Johnny. 2012. The Coding Manual for Qualitative Researchers. London and Thousand Oaks, CA: SAGE Publications.

Schleifer, David, and Michaela DeSoucey. 2015. 'What your consumer wants: Business-tobusiness advertising as a mechanism of market change.' Journal of Cultural Economy 8 (2): 218-234.

Schwarzkopf, Stefan. 2007. "Culture” and the limits of innovation in marketing: Ernest Dichter, motivation studies and psychoanalytic consumer research in Great Britain, 1950s1970s.' Management \& Organizational History 2 (3): 219-236.

Schwarzkopf, Stefan. 2009. 'Discovering the consumer market research, product innovation, and the creation of brand loyalty in Britain and the United States in the interwar years.' Journal of Macromarketing 29 (1): 8-20.

Schwarzkopf, Stefan. 2015. 'Mobilizing the depths of the market: Motivation research and the making of the disembedded consumer.' Marketing Theory 15 (1): 39-57.

Silverstein, Michael. 2006. 'Old wine, new ethnographic lexicography.' Annual Review of Anthropology 35 (1): 481-496. 
Sismondo, Sergio. 2011. An Introduction to Science and Technology Studies. Hoboken, NJ: John Wiley $\&$ Sons.

Söderlund, Magnus, ed. 2014. Marknadsföring och påverkan på konsumenten (1 edn), SIR:s Arsbok 2014. Stockholm: Studentlitteratur.

Solomon, Michael R. 2013. Marketing: Real People, Real Decisions. Upper Saddle River, NJ: Pearson Education.

Spencer, Jonathan, and Alan Barnard. 2002. Encyclopedia of Social and Cultural Anthropology. London: Taylor \& Francis Routledge.

Strathern, Marilyn. 2006. 'A community of critics? Thoughts on new knowledge.' Journal of the Royal Anthropological Institute 12 (1): 191-209.

Suddaby, Roy. 2010. 'Editor's comments: Construct clarity in theories of management and organization.' Academy of Management Review 35 (3): 346-357.

Sunderland, Patricia L, and Rita M. Denny. 2011. 'Consumer Segmentation in Practice: An Ethnographic Account of Slippage.' In Inside Marketing: Practices, Ideologies, Devices, edited by D. Zwick and J. Cayla, pp. 137-161. Oxford: Oxford University Press.

Tadajewski, Mark. 2010. 'Towards a history of critical marketing studies.' Journal of Marketing Management 26 (9-10): 773-824.

Tadajewski, Mark. 2015. 'Focus groups: History, epistemology and non-individualistic consumer research.' Consumption Markets \& Culture 19 (4): 319-345.

Thompson, Craig J., and Elizabeth C. Hirschman. 1995. 'Understanding the socialized body: A poststructuralist analysis of consumers' self-conceptions, body images, and self-care practices.' Journal of Consumer Research 22 (2): 139-153.

Traweek, Sharon. 1988 [1992]. Beamtimes and Lifetimes: The World of High Energy Physicists. Cambridge, MA and London: Harvard University Press.

Turner, Victor. 1987. 'Betwixt and between: The liminal period in rites of passage.' Betwixt and between: Patterns of masculine and feminine initiation, pp. 3-19. n.p. 
Turner, Victor, R. D. Abrahams, and A. Harris. 2011. The Ritual Process: Structure and Anti-Structure. New Brunswick, NJ and London: Aldine Transaction.

Tylor, Edward Burnett. 1871. Primitive Culture: Researches into the Development of Mythology, Philosophy, Religion, Language, Art, and Custom, Vol. 1. London: Murray.

Widmer, Sarah. 2016. 'Experiencing a personalised augmented reality: Users of Foursquare in urban space.' In Algorithmic Life: Calculative Devices in the Age of Big Data., edited by Louise Amoore and Volha Piotukh, pp. 57-71. London and New York: Routledge.

Woodward, Julian L. 1951. 'Public opinion research 1951-1970: A not-too-reverent history.' Public Opinion Quarterly 15 (3): 405-420.

Woolgar, Steve, and Geoff Cooper. 1999. 'Do artefacts have ambivalence? Moses' bridges, Winner's bridges and other urban legends in S\&TS.' Social Studies of Science 29 (3): 433-449.

Woolgar, Steve, and Javier Lezaun. 2013. 'The wrong bin bag: A turn to ontology in science and technology studies?' Social Studies of Science 43 (3): 321-340.

Zwick, Detlev, and Julien Cayla, eds. 2011. Inside Marketing: Practices, Ideologies, Devices: Oxford: Oxford University Press.

Zwick, Detlev, and Janice Denegri Knott. 2009. 'Manufacturing customers: The database as new means of production.' Journal of Consumer Culture 9 (2): 221-247.

Zwick, Detlev, Samuel K. Bonsu, and Aron Darmody. 2008. 'Putting consumers to work: "Cocreation" and new marketing govern-mentality.' Journal of Consumer Culture 8 (2): 163-196. 


\section{Papers}

The papers associated with this thesis have been removed for copyright reasons. For more details about these see:

http://urn.kb.se/resolve?urn=urn:nbn:se:liu:diva-144816 